\title{
INVESTIGATION OF THE ADAPTIVE IMMUNE RESPONSE IN IMMUNE-MEDIATED DISEASES
}

Sonja Dulic MD

PhD Thesis

Doctoral School of Interdisciplinary Medicine

Tutor: Attila Balog MD, PhD

Department of Rheumatology and Immunology

University of Szeged, Faculty of Medicine

Szeged

2018 


\section{List of publications related to the thesis}

\section{Full papers:}

I. Dulic S, Vasarhelyi Z, Sava F, Berta L, Szalay B, Toldi G, Kovacs L, Balog A. T-Cell Subsets in Rheumatoid Arthritis Patients on Long-Term Anti-TNF or IL-6 Receptor Blocker Therapy. MEDIATORS OF INFLAMMATION 2017: Paper 6894374. 19 p. (2017) IF: 3,549

II. Dulic S, Vasarhelyi Z, Bajnok A, Szalay B, Toldi G, Kovacs L, Balog A. The Impact of Anti-TNF Therapy on CD4+ and CD8+ Cell Subsets in Ankylosing Spondylitis. PATHOBIOLOGY 85:(3) pp. 201-210. (2018) IF: 1,592

\section{Citeable abstracts:}

Dulic S, Toldi G, Vásárhelyi B, Balog A The impact of Biologic Therapies on CD4+ and CD8+ Cell Subsets in Rheumatoid Arthritis: A Long Term Follow Up Study. ANNALS OF THE RHEUMATIC DISEASES 75:(Suppl. 2.) pp. 182-183. (2016)

Dulic S, Vásárhelyi Z, Bajnok A, Szalay B, Toldi G, Kovács L, Balog A. Analysis of the T-cell subset composition in ankylosing spondylitis patients with long-standing anti-TNF therapy. ANNALS OF THE RHEUMATIC DISEASES 76:(Suppl.2) p. 780. 1 p. (2017)

\section{Further publications not related to the thesis}

Gál B, Dulic S, Kiss M, Groma G, Kovács L, Kemény L, Bata-Csörgő Z. Increased circulating anti- $\alpha 6$-integrin autoantibodies in psoriasis and psoriatic arthritis but not in rheumatoid arthritis. JOURNAL OF DERMATOLOGY 44:(4) pp. 370-374. (2017) IF: 2,788

Kern A, Balog A, Dulic S, Barabas E, Kiszelak M, Vasarhelyi B. Alterations of the thrombin generation profile in rheumatoid arthritis. JOURNAL OF THROMBOSIS AND THROMBOLYSIS 41: pp. 359-364. (2016) IF: $\mathbf{2 , 1 4 2}$

Rosztoczy A, Izbeki F, Nemeth IB, Dulic S, Vadaszi K, Roka R, Gecse K, Gyokeres T, Lazar G, Tiszlavicz L, Wittmann T. Detailed esophageal function and morphological analysis shows high prevalence of gastroesophageal reflux disease and Barrett's esophagus in patients with cervical inlet patch. DISEASES OF THE ESOPHAGUS 25:(6) pp. 498-504. (2012) IF: 1,642 


\section{Introduction}

Rheumatoid arthritis (RA), ankylosing spondylitis (AS) and inflammatory bowel diseases (IBD) including Crohn's disease (CD) and ulcerative colitis (UC) are chronic immune-mediated diseases affecting large proportions of the population, and leading to serious acute inflammatory conditions and, if insufficiently controlled, to chronic irreversible organ damage and premature death. An important link among these diseases is the pivotal role of tumor necrosis factor- $\alpha$ (TNF- $\alpha)$ in the pathogenesis, and a consequent high benefit of biological therapies targeting TNF- $\alpha$. The adaptive immune system, which is composed of several specialized subtypes of $\mathrm{T}$ - and B-lymphocytes, is also a very important regulator of the abnormal immune processes in all four diseases. In the present thesis, I would like to summarize my research on the alterations of the composition of T-cell subsets in patients with RA, AS and IBD treated with biological therapies. My aim was to translate the results to clinically relevant findings, such as to find determinants of a good therapeutic response to these agents, and to better understand the mechanism of action of biological therapies.

\subsection{Overview of the examined diseases}

\subsubsection{Rheumatoid arthritis}

RA is the most common inflammatory rheumatic disease, affecting at least $0.5 \%$ of the population. Its hallmark is a symmetric polyarthritis, involving virtually all joints with a predilection to small joints of the hand and foot. The synovial inflammatory infiltrate is characterized by activated fibroblast-like synoviocytes, macrophages, T- and B-cells, mast cells and fibroblasts, massive production of proinflammatory cytokines, chemokines, matrix metalloproteinases, as well as pro-angiogenic mediators. The resulting synovial, cartilage and bone degradation will lead to early irreversible articular structural destruction, and without effective therapy, progressive joint damage will lead to permanent disability. The chronic inflammatory state, together with the various extraarticular manifestations, and the premature and accelerated atherosclerosis will lead to high morbidity and shortened life expectancy (1). While conventional synthetic disease-modifying antirheumatic drugs (csDMARDs), including 
methotrexate, leflunomide, sulfasalazine, (hydroxy)chloroquine, azathioprin and cyclosporine, have been effective only in a subset of RA patients, even despite a concomitant long-term corticosteroid therapy in many patients, the introduction of targeted therapies, in particular biological DMARDs (bDMARD), have provided most of the traditional csDMARD-resistant patients with the possibility of long-term remission or low disease activity. Most of the potential adverse effects of bDMARDs can be prevented or counterbalanced with cautious patient follow-up, but infections and the (probably only slightly increased) risk of malignancies, as well as the high cost of these drugs, still remain concerns. It is to be emphasized, however, that only approximately $30-35 \%$ of patients achieved an ACR70 response after 3 months of therapy in the large randomized trials of all biologicals (1). Furthermore, primary or secondary inefficacy is frequently encountered resulting in an average 2-year persistence on anti-TNFs ranging from 55 to $70 \%$ (2). It can be concluded that long-term remission or low disease activity is achieved only in a minority of patients on bDMARD therapy. The prediction of a good clinical response to the particular classes of bDMARDs would therefore be very useful, but the possibilities are quite limited. Clinical predictors of a long-term favourable therapeutic effect of anti-TNFs include male gender, younger age, shorter disease duration, better functional status, non-smoker status, anti-citrullinated peptide antibody (ACPA)- or RF-negativity and concomitant methotrexate therapy (3-6). The value of biomarkers is much less established: low pre-treatment Th17 frequency in peripheral blood (7), lack of an early upregulation of interferon-regulated genes (interferon signature) (8), and high score in a multi-biomarker disease activity test (including serum levels of 12 biomarkers, such as matrix metalloproteinases, adipokines, adhesion molecules, etc.) (9) were found to predict a subsequent favourable therapeutic response (10), but none of these have become validated tools for clinical practice yet.

The immune pathogenesis of RA can be summarized as an uncontrolled proinflammatory process, arising in genetically susceptible subjects in response to various environmental factors. The genetics of RA is polygenic, HLA-DR4 shared epitope carrier persons being at the most significantly increased risk for the development of the disease. Cigarette smoking, potentially through the alteration of the periodontal and bronchial microbiome, and the induction of the production of citrullinated peptides at these mucosal surfaces is currently regarded as the key driver of the production of ACPA, which are not only diagnostic and prognostic markers of RA, but probably have a direct pathogenic role. The presentation of citrullinated peptides and further putative antigens leads to an aberrantly intense and permanent activation of CD4 T- 
helper cells, differentiating predominantly to the Th1 and Th17 phenotypic lineage, and the activated effector cells are key drivers of the complex inflammatory pathways in RA (1).

\subsubsection{Ankylosing spondylitis}

AS belongs to the group of pathogenetically and clinically related diseases called spondylarthropathies, and involves $0.2 \%$ of the adult population. Its axial manifestation implies chronic inflammation of intervertebral small joints and ligamentous insertions, with new bone formation and calcification of ligaments, eventually leading to total spinal immobility due to ankylosis of the intervertebral junctions. Peripheral manifestations include oligo- or polyarthritis, enthesitis (inflammation of insertions of tendons and ligaments) and dactylitis (sausage-like swelling of toes or fingers due to confluent arthritis, tendinitis and enthesitis). Uveitis and gut inflammation constitute the most common extraskeletal manifestations.

TNF- $\alpha$-blocking agents are the mainstay of therapy, as they are able to induce long-term remission in a substantial proportion of AS patients with an inadequate response to nonsteroidal anti-inflammatory drugs (NSAIDs) in axial, and to csDMARDs (in AS methotrexate and sulfasalazine are widely accepted agents) or to local or systemic corticosteroids in peripheral manifestations. Partial remission, as defined by the Assessment of Spondyloarthritis (ASAS) - PR criterion, is achieved by about $75 \%$ of patients with AS (11). Predictors of an effective anti-TNF therapy include younger age, shorter disease duration, higher C-reactive protein (CRP) levels (12), male gender, higher disease activity (measured with ASDAS score), presence of peripheral arthritis and better functional state as assessed by the Schober test (13). AS has a strong genetic predisposition, since $90 \%$ of the patients carry the HLA-B27 haplotype. Our current understanding suggests that the axial and peripheral inflammation is driven by Tcells that excessively produce Th17 and Th1 type cytokines, e.g. interleukin-17 (IL-17), TNF$\alpha$ and interferon- $\gamma(14,48)$. The primary sites inflammation in both axial and peripheral musculoskeletal manifestations are the entheses, where IL-23 induces IL-17 and TNF- $\alpha$ overproduction from resident classical and innate-like T-cells (15). 


\subsubsection{Inflammatory bowel diseases}

Both CD and UC are characterized by severe, chronic gastrointestinal inflammation leading to diarrhea, hematochesia, abdominal pain and weight loss. However, important differences distinguish the two diseases: CD may arise at any site along the gastrointestinal tract, with a marked predominance of the terminal ileum, whereas $20 \%$ of the patients develop colonic involvement. In $20 \%$ of patients, perianal manifestations such as fistulas or abscesses develop. The inflammatory process is segmental and transmural, with severe destructive sequelae with two major patterns: penetrating forms lead to fistula formation, whereas stenosing forms cause bowel obstruction. In contrast, in UC the inflammatory process affects only the mucosa of the colon and rectum, albeit in a continuous manner, with ulceration, cryptitis and microabscesses detected in histology samples. Both diseases are frequently associated with extraintestinal manifestations such as arthritis, erythema nodosum, pyoderma gangrenosum, primary sclerosing cholangitis and uveitis. Anti-TNF therapy is also beneficial in both IBD-s, but the reported incidence of primary nonresponse of 10 to $30 \%$ (16), and the annual risk of secondary nonresponse from $13 \%$ to $20.3 \%$ for adalimumab (17) warn us that more data are required for a better, personalized choice of novel therapies (18).

The immune pathogenesis is also distinct in the two diseases, although the primary abnormalities in both illnesses are a defective mucosal barrier function and an aberrant inflammatory response to gut microbiota. The dysfunctional interaction between the mucosal immune system and the bacterial microflora in the gastrointestinal tract is featured by enhanced initiation of inflammatory immune response by pattern recognition receptors in mucosal dendritic cells and macrophages, and insufficient differentiation toward induced regulatory $\mathrm{T}$ cells (Tregs) (19). While CD is characterized by a skewed differentiation of naive T-cells to the Th1 and Th17 phenotype, and increased amounts of IL-12, Il-15, IL-23, and consequently TNF$\alpha$, interferon- $\gamma$ and IL-17 are detectable in the gut mucosa (20). In contrast, UC the overproduction of IL-4, IL-5 and IL-13 is observed, consistent with an increased Th2 activation (20). 


\subsection{T-cell subset composition in the examined diseases, and the impact of biological therapies on the adaptive immune system phenotype}

\subsubsection{Rheumatoid arthritis}

A large number of studies investigated the distribution of various T-cell subsets in RA, most of them focusing on the major effector T-helper cell phenotypic subtypes. It can be concluded that the frequency of Th1, Th2 and Th17 cells is increased $(21,22)$, while that of regulatory T cells (Treg) is decreased in the peripheral blood of RA patients (23-27).Increased numbers of CD4CD45RO+ memory T-cells were demonstrated in the peripheral blood of RA patients (28), and higher proportions of CD4 or CD8 memory T-cells (CD45RO+) were found to correlate with disease activity and IgM rheumatoid factor levels (29). The number of studies on frequencies of activated T-cells as characterized by the specific early (CD69), intermediate (CD25), or late (HLA-DR) activation markers is very limited, and it can be concluded that the prevalence of these subtypes is higher in RA than in healthy or osteoarthritic controls (30-33).

However, much less is known about how anti-TNF and IL-6-receptor-blocking biological affect the T-cell subset composition. Few studies, including our previous examinations (26), followed T-cell subset prevalence changes during anti-TNF treatment, but in most of them, only short term follow-up was evaluated (34-41), or involved relatively low numbers of patients $(34,35,38,39)$, and the majority were restricted to the determination of Treg and Th17 proportions. Although most of the studies describe an increase in Treg and a decrease in Th17 frequencies $(34,37,38,40)$, opposing results have also been published $(26,36,41)$. As concerns the possibilities of therapeutic response prediction, Chen et al found that Th17 cell counts decrease in anti-TNF-treated patients who had shown a good response to therapy, whereas in non-responders, Th17 cell percentages increased (40). The number of CD8 cells was found to be unchanged during infliximab, an anti-TNF agent, but only 7 patients were investigated (42). In our previous study involving 8 weeks of short term follow-up, we have demonstrated that Th1 and Treg frequencies increased compared with the values measured at the time of the initiation of anti-TNF therapy, but the values remained significantly different from those of healthy controls (26).

Data on the effects of IL-6R blocker therapy are especially limited (43-45). Tocilizumab was found to increase the number of Tregs (43-45), to correct the increased Th17/Treg ratio 
observed in active RA (45) and this change correlated with clinical improvement (43). Pesce et al have reported that Treg prevalence increases during tocilizumab treatment, while Th1 and Th17 frequencies did not change in their cohort (44).

\subsubsection{Ankylosing spondylitis}

Analyses of the peripheral blood T-cell composition has revealed increased percentages of circulating Th17 helper lymphocytes (46) as well as increased numbers of Th2 cells (47), but increased Th1 frequencies have also been reported $(48,49)$. On the other hand, regulatory Tcells (Treg) display decreased prevalence in the blood of AS patients suggesting that their lack may contribute to the pathogenesis of the disease (50). The balance of Th17 and Treg cells has a major impact on $\mathrm{T}$ cell activities during inflammatory rheumatic diseases, such as AS (51), and an increased Th17/Treg ratio was detected in most of the examinations.

There are only few studies addressing the question of how TNF-inhibitors influence the T-cell repertoire in AS $(48,52-55)$. Previous studies from our research group have revealed that the ratio of naïve CD4CD45RA cells decreased, and of memory CD4CD45RO cells increased after 6 weeks of infliximab therapy (54). In a large number of patients, Xiey et al have focused on Th17 and Treg cells, and demonstrated that the prevalence of Th17 decreased and that of Tregs increased in responders, and these values changed exactly in the opposite direction in non-responders (52). Th17 and Th1 cell subsets in anti-TNF-treated patients were lower than in anti-TNF-naive patients and were similar to healthy controls (48). In contrast, another study on 15 AS patients has reported on an increase in Th17 cell prevalence in anti-TNF-treated patients (53). In contradiction to the previous investigations, Liao et al have detected increased Treg frequencies in 15 AS patients, moreover adalimumab therapy has reduced the Treg prevalence (55). Important limitations are, however, that most of the existing examinations have examined only the role of Tregs and/orTh17 cells $(52,53,55)$, and many of the available articles did not make a distinction between peripheral and/or axial AS, and they use non-radiographic spondyloarthritis as an early stage of AS $(49,56)$ rather than as an individually existing entity. Importantly, only one study analyzed patients with relatively long-standing anti-TNF treatment (6 months) (52), whereas two further investigations, including our previous work, followed the T cell repertoire only for short-term (6 weeks) $(53,54)$, although we have already demonstrated in our preceding study of RA patients that there are profound differences in the T cell subset distribution as measured after short-term or long-term follow-up (57). 


\subsubsection{Inflammatory bowel diseases}

Due to its accessibility, much of the studies on the adaptive immune system in IBD took advantage of the possibility of examining the target tissue, i.e. the gastrointestinal mucosal processes. As mentioned before, the gut-associated lymphoid tissue (GALT) of CD patients contains more Th1 cells, predominantly secreting IFN- $\gamma$, as measured by ELISPOT assay, whereas that of UC patients display an abundance of Th2 cells (58). Later, the importance of Th17 cells has also emerged in both IBD-s. In a parallel analysis of intestinal and peripheral blood T-cell phenotype, upregulation of Th17 cells and Tregs in active inflammatory lesions in patients with both CD and UC was detected as compared with quiescent/mildly inflamed lesions and healthy tissue (59). However, more and more data are accumulating that, in addition to classical Th17 cells, the major producers of IL17 are in fact novel and unconventional T-cell subtypes, such as IFN- $\gamma+$ IL17+ coproducing CD4 T cells, that share the transcriptional and cytokine-producing phenotype of Th1 and Th17 cells. Furthermore, these cells may be specifically involved in intestinal inflammation in CD and UC (60). Other such nonconventional cells develop during the bidirectional transition of Th17 and Treg cells, a phenomenon that has excessively been described (61). The importance of this plasticity in IBD was confirmed by $\mathrm{Li}$ et al, who demonstrated high amounts of IL17+ROR $\gamma+$ Tbet+Gata3+FoxP3+ "crossover" T-cells (Treg cells that simultaneously carry the phenotype of other Th subtypes) in the lamina propria of IBD patients, and the prevalence of Treg/Th2 crossover subpopulations was associated with clinical disease scores of both IBDs (62).

Deviations in the peripheral blood T-cell subtypes have also been addressed. Decreased Treg frequency has been demonstrated in several studies both in UC and CD (63-67). In 46 Chinese CD patients, Th1 and Th17 proportions were found to be higher, whereas that of Tregs was lower than in healthy controls (68). The percentages of circulating Th1 (CD3+CD8-IFN$\left.\gamma^{+}\right)$and type-one cytotoxic T cell (Tc1) $(\mathrm{CD} 3+\mathrm{CD} 8+\mathrm{IFN}-\gamma+)$ cells were detected to be higher in patients with active UC than in patients with inactive UC and normal controls, although levels were lower than those in CD (60). HLA-DR+ CD4 and CD8 activated T-cells were found to be increased in the peripheral blood in active IBD (70). The IL17 and FoxP3 doubleexpressing T-cells, mentioned in the previous paragraph, were also demonstrated in the peripheral blood of both CD and UC patients, moreover, with higher prevalence compared with age- and gender-matched controls (71), and the ability of Treg cells to suppress autologous Tcell proliferation was also reduced in this study. Another investigation with potential clinical correlation has found that a decreased CD8CD28+/CD8CD28- ratio indicates a poor prognosis 
in CD (72). A hypothetical explanation for this finding was that these CD8CD28- regulatory CD8 cells shift from the intestinal tissue to the circulation.

During infliximab therapy, Treg cell frequencies did not display any change in the 20 investigated CD patients during 42 days of follow-up (73) or in $26 \mathrm{CD}$ patients after 26 weeks of therapy (74). Treg prevalence was similar to controls both at baseline and at the end of follow-up during anti-TNF therapy. In contrast, Di Sabatino et al have found in their measurements on $20 \mathrm{CD}$ patients that Treg frequency at the start of anti-TNF therapy was significantly higher in $\mathrm{CD}$ patients who later proved to be nonresponders than in responder patients. Clinical improvement in $12 \mathrm{CD}$ patients was associated with a significant increase of Treg frequency after 10 weeks (75). Another study also obtained similar results (76). In contrast, in the study of Dige et al, high baseline Treg levels were predictive of a good response to anti-TNF (74). In further contradiction, Li et al and also Guidi et al did find an increase of Treg prevalence during infliximab therapy, but this was significantly more pronounced in responders $(77,78)$, or was detectable only in responders (79). Moreover, clinical response was associated with a parallel decrease of Tregs in the inflamed mucosa (77). Treg frequency also increased when it was measured 14 days after a single infliximab infusion (80). Importantly, all three groups analyzed CD and UC patients taken together. Grundström et al followed the levels of Th1, Th2, Th17, Treg (FoxP3+), CD69 and CD25 positive cells during adalimumab treatment in 20 IBD patients, and found no change over 6 weeks of therapy (81). Again, the results of CD and UC patients were not analyzed separately, and the authors reported that they detected no CD69 staining on peripheral blood lymphocytes, only in mucosal biopsies performed on 4 of the patients, in whom the proportion of this subset increased in the inflamed tissue by 6 weeks.

\section{Aims}

In view of the cardinal role of $\mathrm{T}$ cells in host defense, anti-tumor surveillance and immune homeostasis, we regarded it important to know how the composition of the T cell repertoire is skewed during TNF-blocker therapies, since these agents are usually applied for several years. The majority of studies on the effect of anti-TNF or - in RA - IL6R-blocker therapies on the T-cell homeostasis carry the limitations of low patient number, a restricted focus on selected Tcell subtypes - most often on effector T-helper cell phenotypic subsets - instead of a comprehensive overview, and of short follow-up- although changes in T-cell subpopulation proportions are expected to occur after longer time in view of the life-span of the cells. We 
therefore aimed at the investigation of a wide scope of T-cell subtypes in anti-TNF-treated patients stratified as responders and non-responders, after a sufficiently long treatment duration. Our purpose was to gain a more precise insight into the mechanism of action of anti-TNF drugs, and, through the correlation of the laboratory data with the clinical characteristics and disease course, to find predictors to a favourable therapeutic response to these agents.

Specifically our aims were:

1. To recruit RA, AS, CD and UC patients with active disease before the initiation of anti-TNF - and in RA, IL6R-blocker - biological therapy

2. To measure the prevalences of total CD4 and CD8 cell proportions, and frequencies of naïve and memory, early (CD69+), intermediate (CD25+) and late (HLA-DR+) activated subsets within both CD4 and CD8 cells, and Th1, Th2, Th17 and Treg subtypes.

3. To perform repeat measurements after at least 3 months of biological therapy

4. To compare the baseline results with a) healthy controls, b) treatment-naïve newly-diagnosed cases with active disease

5. To compare the follow-up results a) between patient subgroups of responders and nonresponders to biological therapy, b) with baseline values from the same patient, c) and with our previous results of short-term-treated patients (in RA and AS)

6. To correlate the results with the clinical parameters and disease course on biological therapy, and to seek for predictor biomarkers for therapeutic response

\section{Patients and methods}

\subsection{Rheumatoid arthritis}

In the rheumatoid arthritis study 92 patients were evaluated, the disease was classified according to the 2010 ACR/EULAR Classification Criteria for Rheumatoid arthritis (82). Forty-nine patients were treated with anti-TNF therapy (adalimumab: 14, certolizumab pegol: 14, etanercept: 11, infliximab: 6, golimumab: 4 patients), and 43 with the anti-IL-6R agent tocilizumab. Within the anti-TNF-treated patients, we distinguished two groups; anti-TNFresponder and anti-TNF-non-responder patients, in the tocilizumab group we only evaluated responder patients, because of the low number of non - responder ones. For define therapeutic response, we used the EULAR good response criteria (83), therefore in the responder group, 
patients had a DAS28 score of $\leq 3.2$, and the improvement was $>1.2$ in DAS28. The detailed clinical data and patient characteristics are presented in Table1. For the control group we included 30 age- and gender-matched healthy volunteers. Informed consent was signed by all participants, and the protocol had been approved by the Ethics Committee of the Ministry of Health of Hungary and ethical committee of the University of Szeged (ETT-TUKEB905/PI/09).

\begin{tabular}{|c|c|c|c|c|}
\hline & $\begin{array}{l}\text { Anti-TNF } \\
\text { responders } \\
\quad(n=30)\end{array}$ & $\begin{array}{c}\text { Anti-TNF } \\
\text { non-responders } \\
(n=19)\end{array}$ & $\begin{array}{l}\text { Anti-IL-6R } \\
\text { responders } \\
(n=43)\end{array}$ & $\begin{array}{c}\text { Newly diagnosed } \\
\text { untreated RA } \\
(\mathbf{n}=19)\end{array}$ \\
\hline Mean age (range) & $57.2(26-75)$ & $55.7(29-71)$ & $57.5(34-76)$ & 48.3 (22-67) \# \\
\hline Gender (female/male) & $19 / 11$ & $12 / 7$ & $28 / 15$ & $11 / 8$ \\
\hline $\begin{array}{r}\text { Anti-TNF treatments n(\%) } \\
\text { adalimumab } \\
\text { certolizumab } \\
\text { etanercept } \\
\text { infliximab } \\
\text { golimumab }\end{array}$ & $\begin{array}{c}30(100.0) \\
10(33.3) \\
6(20.0) \\
7(23.3) \\
4(13.3) \\
3(10.0)\end{array}$ & $\begin{array}{c}19(100.0) \\
4(21.1) \\
8(42.1) \\
4(21.1) \\
2(10,5) \\
1(5,3)\end{array}$ & & \\
\hline $\begin{array}{r}\text { Mean disease duration } \\
\text { (range) }\end{array}$ & $11.3(2-33) \mathrm{yrs}$ & $10.8(4-44) \mathrm{yrs}$ & $12.0(2-34) \mathrm{yrs}$ & 2.7 (1-3) months \\
\hline $\begin{array}{r}\text { Mean duration } \\
\text { of current biologic therapy } \\
\text { - months (range) }\end{array}$ & $29.8(6-52)$ & $30.95(6-50)$ & $33.0(6-48)$ & - \\
\hline $\begin{array}{r}\text { Prior use of TNF } \\
\text { inhibitors } \\
\text { No. of switching.n: } 1 \\
2 \\
3\end{array}$ & $\begin{array}{c}3 / 30 \\
3 / 3 \\
- \\
-\end{array}$ & $\begin{array}{c}6 / 19 \\
4 / 6 \\
2 / 6 \\
-\end{array}$ & $\begin{array}{c}29 / 43 \\
15 / 26 \\
9 / 26 \\
5 / 26\end{array}$ & - \\
\hline $\begin{array}{r}\text { Patients on corticosteroid } \\
\text { therapy } n(\%)\end{array}$ & $8(26.7)$ & $8(42.1)$ & $15(40.5)$ & - \\
\hline $\begin{array}{r}\text { Patients on conventional } \\
\text { DMARD therapy n (\%) }\end{array}$ & $26(86.7)$ & $15(79.0)$ & $23(62.2)^{*}$ & - \\
\hline ACPA-positivity n (\%) & $24(85.4)$ & $14(82.4)$ & $21(41.4)^{*}$ & $19(100.0)$ \\
\hline DAS28 score $($ mean \pm SD) & $2.2 \pm 0.8$ & $5.12 \pm 1.29+$ & $1.89 \pm 0.87$ & $7.71 \pm 4.06 \#$ \\
\hline
\end{tabular}

Table 1. Clinical data and patient characteristics.

$* p<0.05$ between anti-TNF-responders and IL6R-blocker responders. $+p<0.05$ between antiTNF non-responders and IL6R-blocker responders, \#p<0.05 between newly diagnosed untreated RA group and all other groups; DMARD: disease-modifying anti rheumatic drug, 
ACPA: anti-citrullinated protein antibody, DAS28: Disease Activity Score with 28 joints, TNF: tumor necrosis factor- $\alpha, I L-6 R$ : interleukin-6 receptor

\subsection{Ankylosing spondylitis}

Twenty-two AS patients were enrolled in this study, who had been treated with anti TNF therapy for more than six months. AS was classified according to the Modified New York Criteria for AS (84). We distinguished anti-TNF-responder or anti-TNF-non-responder patients; and for the definition of the therapeutic response, we used the ASAS 5/6 improvement criteria (85) and for remission we followed the ASAS remission criteria set (86). Among these examined patients in the responder group, 6 received infliximab, 7 adaimumab, and 2 etanercept. In the non- responder group, there were 3 infliximab-, 4 adalimumab-, one etanercept- and one golimumab-treated patient. We recorded the HLA-B27 status, the presence of peripheral arthritis (in addition to the axial involvement), enthesitis, uveitis, inflammatory bowel disease (IBD) ever occurring during the course of the disease, the grade of sacroiliitis and the presence of AS-specific radiographic changes on the spine (syndesmophyte or bamboospine), and smoking ever in every patient. Parameters of disease activity (C-reactive protein (CRP), erythrocyte sedimentation rate (ESR), BASDAI) and functional status (BASFI) were also registered. In the control group we enrolled 10 age- and gender-matched healthy volunteers as we did in our previous study. Informed consent was signed by all participants. Study protocol had been approved by the Ethics Committee of the Ministry of Health of Hungary and ethical committee of the University of Szeged (ETT-TUKEB905/PI/09). We compared the long term effects of biological treatment with treatment naive and short term treated AS patients using our previous work (54).Clinical characteristics are detailed in Table 2 


\begin{tabular}{|l|c|c|}
\hline & $\begin{array}{c}\text { anti-TNF treated } \\
\text { responders (n=15) }\end{array}$ & $\begin{array}{c}\text { anti-TNF treated non- } \\
\text { responders (n=7) }\end{array}$ \\
\hline Age (yrs) & $46(31-63)$ & $41(30-57)$ \\
\hline Disease duration (months) & $15(9-40)$ & $6(940)$ \\
\hline $\begin{array}{l}\text { anti-TNF therapy duration } \\
\text { (months) }\end{array}$ & $6(6-12)$ & $3(43)$ \\
\hline Smoking ever & $7(47)$ & $5(71)$ \\
\hline HLA-B27 positivity & $11(73)$ & $3(43)$ \\
\hline Presence of peripheral & $10(67)$ & $3(43)$ \\
arthritis & $2(13)$ & $1(14)$ \\
\hline Presence of enthesitis & $5(33)$ & $2.57(2-4)$ \\
\hline Presence of uveitis & $2(13)$ & $5(71)$ \\
\hline Presence of IBD & $2.67(2-4)$ & $37(2-100)$ \\
\hline Radiographic SI index & $10(67)$ & $52(5-67)$ \\
\hline Presence of radiographic \\
abnormalities on the spine
\end{tabular}

Table 2. Clinical characteristics of long-term anti-TNF-treated AS patients

Numbers indicate mean (range) or absolute numbers (\%). AS: ankylosing spondylitis IBD: inflammatory bowel disease, CRP: C-reactive protein, ESR: erythrocyte sedimentation rate, BASDAI: Bath Ankylosing Spondylitis Activity Index, BASFI: Bath Ankylosing Spondylitis Functional Index. * $p<0.05$ 


\subsection{Inflammatory bowel disease}

We enrolled 114 IBD patients, who were all treated at First Department of Internal Medicine University of Szeged. The first part of this study was a prospective follow-up of CD and UC patients, in whom anti-TNF therapy was initiated. The second one was a cross-sectional comparison of the immune phenotype of IBD patients on established anti-TNF therapy, grouped as anti-TNF-responders and non-responders; these data were compared with results from active, therapy-naïve and inactive (treated) IBD patients.

In the prospective part $\mathrm{CD}$ and UC patients ( $\mathrm{n}=16$ for each disease) were enrolled, in whom the disease was active despite therapy with non-biologic immunosuppressive therapies, and in whom anti-TNF therapy was initiated after blood sampling (abbreviated as CDstart or UCstart group). All patients had a Crohn's Disease Activity Index (CDAI) (87) > 220 (88) or Mayo score $>$ (89). Patients were classified to disease subsets following the Montreal classification criteria (90).

During subsequent follow-up, treatment was conducted following the best clinical judgement of the treating physician, and data on the subsequent disease activity and therapy were recorded. Short-term (3 months) and long-term (12 months) response to anti-TNF therapy was assessed, with response defined as a reduction of $>50 \%$ in CDAI, or, for UC patients, in the Mayo score, or - when endoscopy was not performed at the time of assessment - in the partial Mayo (pMayo) score $(91,92)$ without an increase in the anti-TNF dose above standard dose. Non-response (primary or relapse) was established if these activity index-based criteria were not fulfilled, or, based on the clinical assessment of the treating physician, corticosteroid had to be introduced, or its dose had to be increased, or anti-TNF dose had to be increased overstandard dose, or surgical intervention has become necessary, or anti-TNF therapy had to be switched to either another anti-TNF or to a biological of different class. The length of the response period was also recorded. For reimbursement requirements, in some patients at stable remission after 12 months of anti-TNF therapy, the drug was discontinued, and only non-biological maintenance therapy was continued. Disease course after such forced therapy withdrawal was also followedup. In 6 patients from each disease group, control blood sampling was performed after at least 3 months of anti-TNF therapy, and the same laboratory examinations were repeated.

In the cross-sectional part, patients on established ( $>3$ months' duration) anti-TNF therapy were also involved, and their results were compared with those of the members of CDstart or UCstart groups. Thirty-one patients with $\mathrm{CD}$ and 16 with UC were included, and were 
distinguished as responders (CDresp or UCresp) or non-responders (CDnonresp or UCnonresp) to anti-TNF therapy as defined following the response criteria described in the previous paragraph. The six patients in either the CDstart or UCstart groups, in whom repeated laboratory examinations were performed during anti-TNF treatment, were also involved in the responder or non-responder groups for comparison with the anti-TNF starter groups.

As controls, the following groups were formed and analyzed: 1) patients with newly diagnosed, active, untreated CD or UC: CDnew $(n=7)$, UCnew $(n=7) ; 2)$ patients with inactive disease controlled with non-biologic immunosuppressive drugs: CDinact $(n=14)$, UCinact $(n=7)$, and 3) age- and sex-matched healthy controls $(n=30)$. All participants gave their informed consent, and the study was conducted in concert with the principles of the Helsinki declaration.

The demographic and most important clinical data of the patients in all subgroups are summarized in Table 3.Patient subgroups for both diagnoses were similar in terms of age, disease duration, frequency of extraintestinal manifestations, type of anti-TNF, other therapies ever used, or smoking status. Although there were numerical differences among the groups in terms of gender distribution, these were not statistically significant. However, CDinact patients less frequently had perianal manifestations than anti-TNF-treated CD patients (both responders and non-responders), and anti-TNF therapy duration was shorter in UCnonresp patients than in UCresp patients. 


\begin{tabular}{|c|c|c|c|c|c|c|c|c|c|c|}
\hline & $\begin{array}{c}\text { CDstart } \\
(n=16)\end{array}$ & $\begin{array}{c}\text { CDresp } \\
n=23\end{array}$ & $\begin{array}{c}\text { CDnon } \\
\text { resp } \\
n=8\end{array}$ & $\begin{array}{c}\text { CDnew } \\
\mathrm{n}=7\end{array}$ & $\begin{array}{c}\text { CDinact } \\
n=14\end{array}$ & $\begin{array}{c}\text { UCstart } \\
n=16\end{array}$ & $\begin{array}{c}\text { UCresp } \\
n=10\end{array}$ & $\begin{array}{c}\text { UCnon } \\
\text { resp } \\
n=6\end{array}$ & $\begin{array}{c}\text { UCnew } \\
\mathbf{n}=7\end{array}$ & $\begin{array}{c}\text { UCinact } \\
\mathbf{n}=7\end{array}$ \\
\hline Age & $\begin{array}{c}30(18- \\
48)\end{array}$ & $39(20-66)$ & $\begin{array}{c}31(19- \\
48)\end{array}$ & $\begin{array}{c}31(25- \\
44)\end{array}$ & $\begin{array}{c}37(23- \\
59)\end{array}$ & $42(20-65)$ & $\begin{array}{c}40(19- \\
59)\end{array}$ & $\begin{array}{c}38(21- \\
53)\end{array}$ & $\begin{array}{c}36(23- \\
48)\end{array}$ & $\begin{array}{c}43(26- \\
61)\end{array}$ \\
\hline Female/male & $7 / 9$ & $13 / 10$ & $3 / 5$ & $3 / 4$ & $2 / 12$ & $7 / 9$ & $3 / 7$ & $5 / 1$ & $3 / 4$ & $1 / 6$ \\
\hline $\begin{array}{l}\text { Disease } \\
\text { duration } \\
\text { (month) }\end{array}$ & $\begin{array}{l}82(7- \\
236)\end{array}$ & $132(8-410)$ & $\begin{array}{l}121 \\
(17- \\
235)\end{array}$ & $14(0-72)$ & $\begin{array}{l}77(5- \\
204)\end{array}$ & $105(6-389)$ & $\begin{array}{c}117(11- \\
290)\end{array}$ & $\begin{array}{c}75(13- \\
180)\end{array}$ & $3(1-6)$ & $\begin{array}{c}134(35- \\
288)\end{array}$ \\
\hline $\begin{array}{l}\text { Any extra- } \\
\text { intestinal } \\
\text { manifest. }\end{array}$ & 1 & 2 & 0 & 2 & 0 & 2 & 0 & 2 & 1 & 1 \\
\hline $\begin{array}{l}\text { Smoking } \\
\text { never } \\
\text { past } \\
\text { present }\end{array}$ & $\begin{array}{l}5 \\
1 \\
8\end{array}$ & $\begin{array}{l}9 \\
2 \\
9\end{array}$ & $\begin{array}{l}4 \\
1 \\
3\end{array}$ & $\begin{array}{l}5 \\
0 \\
1\end{array}$ & $\begin{array}{l}9 \\
1 \\
3\end{array}$ & $\begin{array}{l}8 \\
6 \\
1\end{array}$ & $\begin{array}{l}5 \\
2 \\
1\end{array}$ & $\begin{array}{l}3 \\
1 \\
1\end{array}$ & $\begin{array}{l}5 \\
1 \\
1\end{array}$ & $\begin{array}{l}0 \\
3 \\
2\end{array}$ \\
\hline $\begin{array}{l}\text { CD Montreal } \\
\text { class. } \\
\text { A1/2/3 } \\
\text { L1/2/3/4 } \\
\text { B1/2/3 } \\
\text { Perianal Y/N }\end{array}$ & $\begin{array}{c}2 / 12 / 2 \\
2 / 2 / 10 / 2 \\
5 / 6 / 5 \\
8 / 8\end{array}$ & $\begin{array}{c}3 / 16 / 4 \\
2 / 3 / 16 / 2 \\
6 / 9 / 8 \\
16 / 7\end{array}$ & $\begin{array}{c}1 / 7 / 0 \\
1 / 0 / 7 / 0 \\
3 / 2 / 3 \\
6 / 2\end{array}$ & $\begin{array}{c}0 / 7 / 0 \\
3 / 2 / 2 / 0 \\
3 / 2 / 2 \\
3 / 4\end{array}$ & $\begin{array}{c}3 / 8 / 3 \\
2 / 3 / 8 / 1 \\
6 / 6 / 2 \\
1 / 13^{+}\end{array}$ & & & & & \\
\hline $\begin{array}{l}\text { UC Montreal } \\
\text { class } \\
\text { L1/2/3 }\end{array}$ & & & & & & $1 / 4 / 11$ & $0 / 5 / 5$ & $0 / 2 / 4$ & $3 / 1 / 3$ & $1 / 2 / 4$ \\
\hline $\begin{array}{l}\text { Current anti- } \\
\text { TNF: } \\
\text { infliximab/ } \\
\text { adalimumab }\end{array}$ & & $16 / 7$ & $7 / 1$ & & & & $8 / 2$ & $6 / 0$ & & \\
\hline $\begin{array}{l}\text { Duration of } \\
\text { current anti- } \\
\text { TNF }\end{array}$ & & $18(4-57)$ & $\begin{array}{c}26(9- \\
62)\end{array}$ & & & & $11(4-26)$ & $\begin{array}{l}4(3- \\
6)^{*}\end{array}$ & & \\
\hline Prior anti-TNF & 3 & 9 & 2 & & & 1 & 5 & 2 & & \\
\hline $\begin{array}{l}\text { Corticosteroid } \\
\text { (ever) }\end{array}$ & 6 & 3 & 3 & 0 & 4 & 10 & 4 & 5 & 0 & 1 \\
\hline $\begin{array}{l}\text { 5-ASA/SSZ } \\
\text { (ever) }\end{array}$ & 8 & 4 & 1 & 0 & 3 & 8 & 7 & 1 & 0 & 4 \\
\hline AZA (ever) & 13 & 12 & 6 & 0 & 13 & 12 & 6 & 2 & 0 & 4 \\
\hline Surgery & 7 & 17 & 5 & 0 & 6 & 1 & 1 & 0 & 0 & 0 \\
\hline
\end{tabular}

Table 3 .Demographic and clinical data of the different cohorts of IBD patients

Numbers indicate mean (range), or number of patients. Extraintestinal manifestation: musculoskeletal, cutaneous, ocular or hepatobiliary. Prior anti-TNF indicates the number of patients in whom anti-TNF therapy was already applied, but had been stopped at least 12 months before the current therapy was initiated. Smoking habit data were missing in 13patients. 5-ASA: 5-amino-salycylic acid, SSZ: sulfasalazine, AZA: azathioprine. For the explanation of the abbreviations of patient subgroups, please see the Patients section. ${ }^{+} p<0.05$ for comparison of CDinact with CDresp and CDnonresp; * $p<0.05$ for comparison of UCresp vs UCnonresp 


\subsection{Methods}

\subsubsection{Laboratory methods - Flow Cytometry}

Anticoagulated blood samples were taken - fifteen milliliters - and peripheral blood mononuclear cells (PBMCs) were separated by centrifugation with Ficoll-Paque (GE Healthcare Life Sciences, Pittsburgh, PA, USA). PBMCs were frozen and kept at $-80{ }^{\circ} \mathrm{C}$ until examination. After thawing, samples were washed twice with phosphate-buffered saline solution (pH 7.4). The following fluorescent antibodies (Becton Dickinson, San Diego, CA, USA) were applied for cell surface staining for $\mathrm{T}$ cell subtype differentiation: helper $\mathrm{T}$ cells (CD4+), Th1 cells (CD4+CXCR3+), Th2 cells (CD4+CCR4+), Th17 cells (CD4+CCR4+CCR6+), Tregs (CD4+CD25highCD127-), naive T cells (CD4+CD45RA+), or memory T cells (CD4+CD45RO+). The proportion of cells expressing the early (CD69), or the late (HLA-DR) activation markers were also determined within both the CD4+ and CD8+ subsets. An average of 200.000 cells was registered for each acquisition. All measurements were performed on a BD FACSAria flow cytometer (BectonDickinson, San Jose, CA, USA). Cell proportion values were allocated with conventional gating, through the use of FACSDiva software (BectonDickinson, San Jose, CA, USA).

\subsubsection{Statistical methods}

Clinical data were presented as mean (range), whereas cell subtype prevalence values as mean $\pm \mathrm{SD}$ or median (25-75 percentile) depending on the distribution of the values. Cell subset percentage values were compared among groups with two-sample t-test or Mann-Whitney test if two groups were compared, or with analysis of variance or with Kruskal-Wallis test, with Bonferroni's or Dunn's tests for multiple comparisons, respectively, if more than two groups were analyzed. We have applied the ANOVA for the comparison of all the patient subgroups and healthy controls. Frequencies were compared with Fisher exact test or chi- squared test. Receiver-operated curve (ROC) analyses were performed to seek for values of baseline (i.e. the start of anti-TNF) cell percentages that would discriminate between patients in whom long-term remission was achieved in response to anti-TNF therapy, and Pearson's correlation analysis was performed to assess the correlation between cell frequency values at the start of anti-TNF and the length of a subsequent remission. A p value $<0.05$ was taken statistically significant in every study. 


\section{Results}

\subsection{Rheumatoid arthritis}

4.1.1. T-cell subset distribution of patients with RA on long-standing anti-TNF therapy

The proportions and ratios of various $\mathrm{T}$ cell subsets are demonstrated in Table 4 and Figures 1 and 2 .
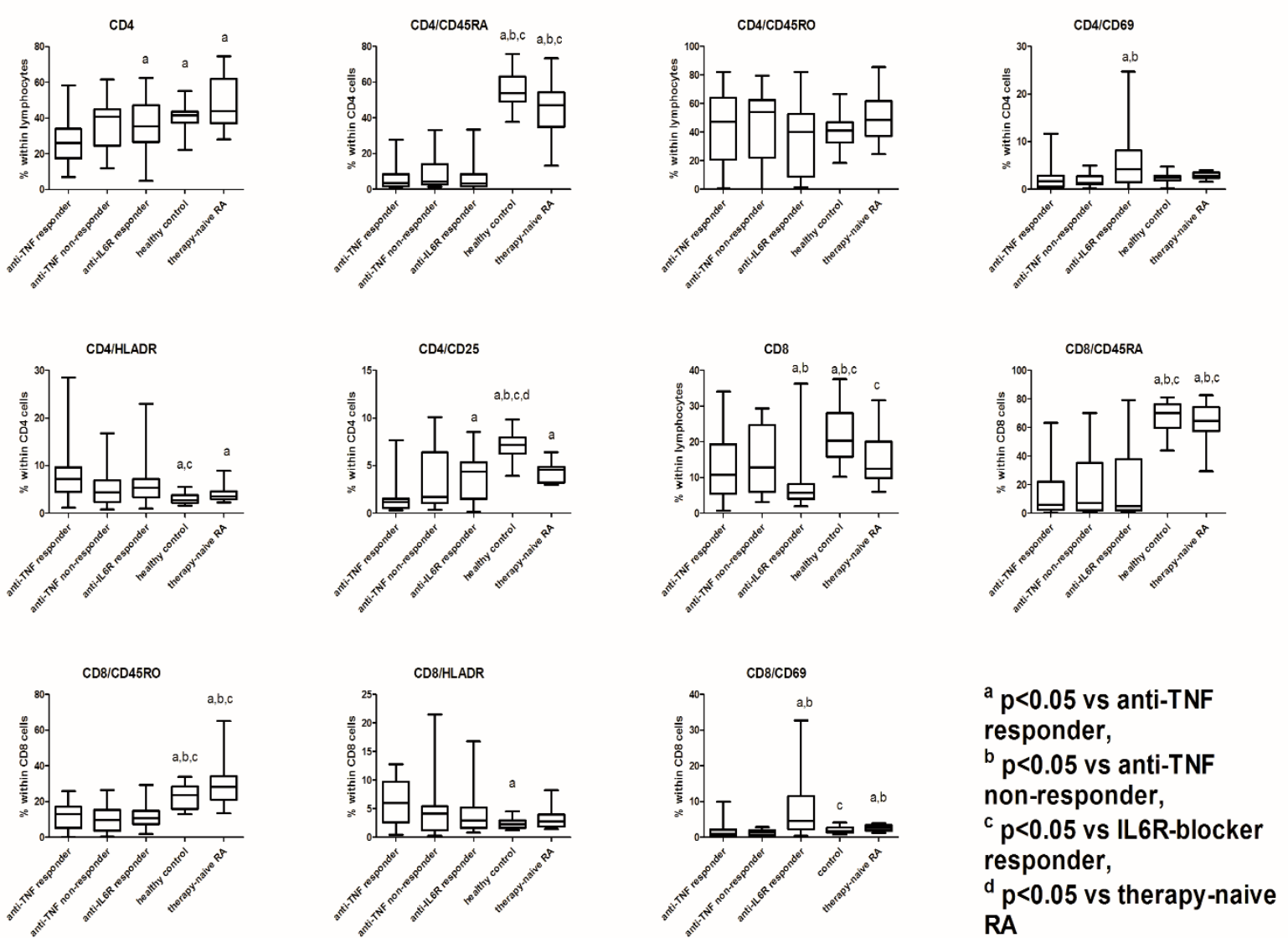

Figure 1. Prevalences of various T-cell subsets in rheumatoid arthritis patient groups of antiTNF-responders (n=30), anti-TNF-non-responders $(n=19)$ and IL-6R-blocker-responders ( $n=43)$, early, active, therapy-naïve RA patients $(n=19)$, and in healthy controls $(n=30)$.

Data are presented as median (horizontal line within boxes), 25 and 75 percentile (horizontal borders of the boxes), and minimum and maximum (whiskers). a $p<0.05$ vs anti-TNF responder, $b p<0.05$ vs anti-TNF non-responder, $c p<0.05$ vs IL6R-blocker responder, $d p<0.05$ vs early, untreated RA patients 

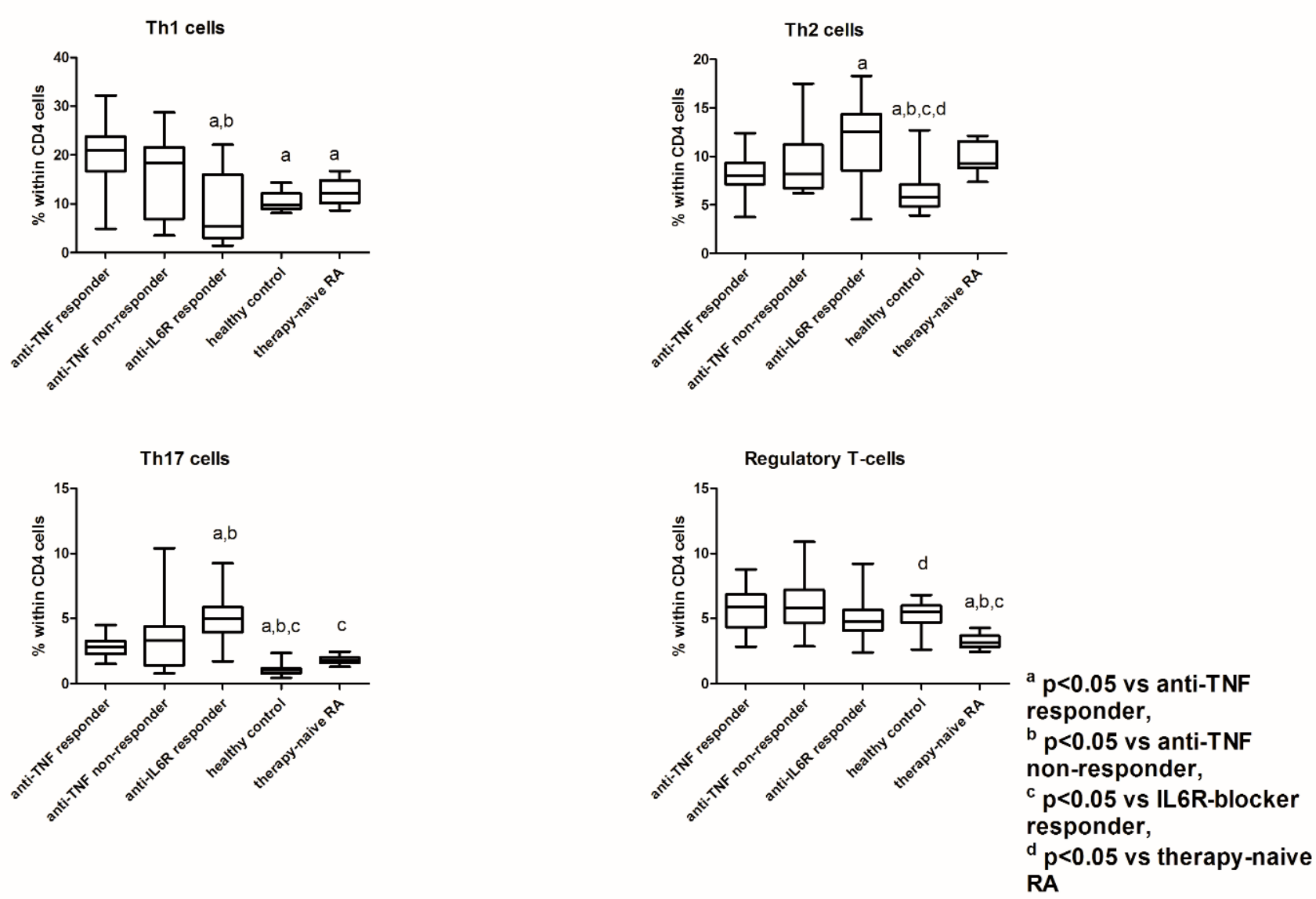

Figure 2. Proportions of the major effector T-helper cell subsets in rheumatoid arthritis patient groups of anti-TNF-responders $(n=30)$, anti-TNF-non-responders $(n=19)$ and IL-6R-blockerresponders ( $n=43)$, early, active, therapy-naïve $R A$ patients $(n=19)$, and in healthy controls $(n=30)$.

Data are presented as median (horizontal line within boxes), 25 and 75 percentile (horizontal borders of the boxes), and minimum and maximum (whiskers). a $p<0.05$ vs anti-TNF responder, $b p<0.05$ vs anti-TNF non-responder, c p<0.05 vs IL6R-blocker responder, $d p<0.05$ vs early, untreated RA patients 


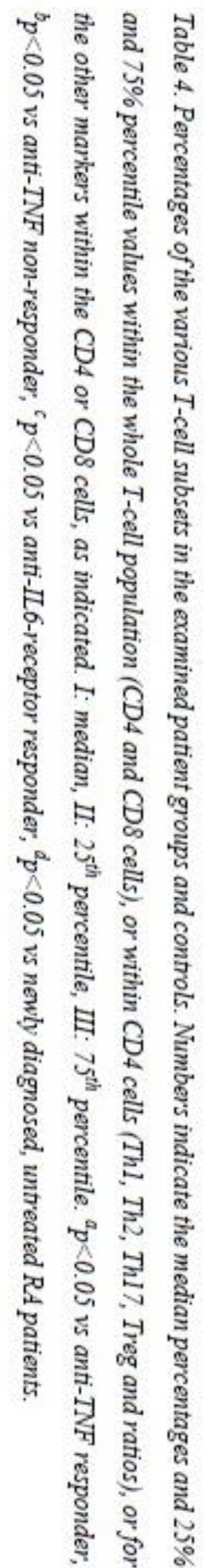

\begin{tabular}{|c|c|c|c|c|c|c|c|c|c|c|c|c|c|c|c|}
\hline \multicolumn{3}{|c|}{$\begin{array}{l}\text { Healthy } \\
\text { controls }\end{array}$} & \multicolumn{3}{|c|}{$\begin{array}{l}\text { Newly diagnosed } \\
\text { untreated patients }\end{array}$} & \multicolumn{3}{|c|}{$\begin{array}{l}\text { alL-6R- } \\
\text { responders }\end{array}$} & \multicolumn{3}{|c|}{$\begin{array}{l}\text { anti- TNF non- } \\
\text { responders }\end{array}$} & \multicolumn{3}{|c|}{$\begin{array}{l}\text { anti-TNF } \\
\text { responders }\end{array}$} & \\
\hline 目 & 부 & $\rightarrow$ & 日 & ㅂ & $\rightarrow$ & 目 & ㅂ. & $\rightarrow$ & 目 & ㅂ & $H$ & 目 & ㅂ & 7 & \\
\hline 帝 & : & 壳 & 엽 & 밈 & to & 亳 & 奚 & 㟧 & 索 & 녕 & $\underset{⿱ 乛}{\mathbf{t}}$ & 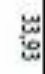 & : & is & \\
\hline 엽 & 索 & g & 象 & : & ts & 婷 & 롭 & 岁 & 氧 & 붕 & $\vec{t}$ & 点 & 호 & $\frac{\omega}{c}$ & 羿 是 \\
\hline 索 & "ू. & 壳 & 옇 & 변 & 索 & : & : & 喜 & 옹 & 봏 & $\stackrel{\breve{s}}{8}$ & : & : & 龺 & 翏 悬 \\
\hline 붔 & 몬 & 노 & 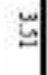 & 녕 & 3 & 용 & 홍 & 索 & 녕 & 홍 & 혛 & : & 영 & 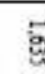 & 8 \\
\hline 㑳 & 热 & है & 融 & : & $\frac{w}{2}$ & 혛 & "ّँّ & $\ddot{s}$ & 읗 & 눙 & 产 & 잏 & t & है & 易 茞 \\
\hline 楬 & 홉 & $\overrightarrow{\mathrm{g}}$ & 夌 & $\breve{5}$ & $\hat{y}$ & 형 & 둉 & 衷 & 영 & 용 & $\bar{y}$ & $\overline{\mathrm{s}}$ & 형 & 5 & 惫 \\
\hline 눈 & : & 홍 & 영 & ๘) & 营 & : & + & 코ำ & 월 & 양 & 察 & : & 军 & : & \\
\hline$=$ & 范 & 영 & 궀 & : & o & 릴 & 옿 & 萦 & 厸 & 봉 & $\overrightarrow{\vec{s}}$ & $\frac{3}{8}$ & 氙 & 8 & 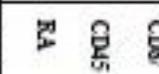 \\
\hline 绨 & 5 & 녕 & 荺 & 봉 & 范 & 농 & ัㅕํ & 형 & : & 幽 & : & 5 & : & 5 & 止 是 \\
\hline 웅 & 형 & 는 & 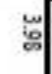 & $\overrightarrow{5}$ & ت군 & 范 & $\overrightarrow{\mathrm{g}}$ & $\begin{array}{l}\text { 잉 } \\
\text { g }\end{array}$ & 站 & 홍 & $\frac{5}{8}$ & to & 명 & $\frac{9}{8}$ & 易 苾 \\
\hline : & 논 & 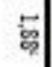 & ్ㅐㅆ & ज & 늘 & 붕 & 봉 & 孝 & 옹 & 営 & 䒯 & $\stackrel{2}{3}$ & 옹 & : & 题 \\
\hline 분 & 窝 & 홍 & 芠 & 훙 & 듬 & 형 & 䋇 & 管 & 영 & 양 & 票 & 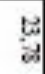 & 명 & $\frac{5}{8}$ & \\
\hline 훙 & 鰓 & $\tilde{\xi}$ & 붛 & $\stackrel{\infty}{9}$ & ํㅜㅇ & ⿹ㅛ & : & 홍 & 홍 & ㅎㅎㅎ & $\frac{0}{8}$ & i: & 는 & 咩 & \\
\hline 붑 & 월 & 홍 & $\overrightarrow{8}$ & 형 & क्ष & 管 & 咹 & 产 & 索 & ⿹ㅎㅎ & $\tilde{t}$ & 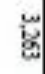 & 농 & 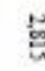 & \\
\hline : & 㪈 & 봉 & : & 븡 & 焉 & 형 & 葶 & 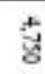 & 봏 & 新 & $\widetilde{\xi}$ & 영 & 善 & है & \\
\hline
\end{tabular}


Anti-TNF-responders

Anti-TNF-responders had lower proportions of CD4 cells, naïve CD4 and CD8 cells and memory CD8 cells, and higher percentages of activated CD4HLA-DR T-cells, but lower prevalences of activated CD4CD25 and of activated CD8CD69 T-cells than early, active, untreated RA patients. Anti-TNF responders were characterized by higher Th1 and Treg frequencies than early, active, untreated RA patients.

When compared with healthy controls, anti-TNF responders had lower prevalences of CD4 and CD8 T-cells. The frequencies of naive T-cells (both CD4CD45RA and CD8CD45RA cells) were lower than in controls, whereas those of the memory subtype (CD45RO) were similar among CD4 cells, and were also lower among CD8 cells in the anti-TNF responders than in healthy volunteers. The proportion of activated T-cells bearing the CD25 marker was lower and that of the HLA-DR-positive cells (both CD4 and CD8) was higher in anti-TNFresponders than in controls (Figure 1). In anti-TNF-responders, Th1, Th2 and Th17 proportion values were all higher than in healthy controls, but, importantly, Treg frequencies were not different (Figure 2).

\section{Anti-TNF-non-responders}

There are somewhat less differences between the T-cell composition of anti-TNF nonresponders and early, untreated RA patients, but naïve T-cells (both CD4 and CD8) and also CD8 memory cells were less prevalent in anti-TNF non-responders, similarly to CD8CD69 activated cells. Comparison with healthy controls also revealed that anti-TNF non-responders had lower proportions of CD4 and CD8 naïve and CD8 memory T-cells, furthermore, CD4CD25 activated T-cells also occurred less frequently in the anti-TNF-non-responders than in the healthy subjects. The percentage of CD8 cells was lower in anti-TNF non-responders than in controls, but, in contrast with anti-TNF responders, CD4 cell prevalence was not different from controls (Figure 1). Similarly to the anti-TNF-responders, Th17 and Th2 percentages were also higher in non-responders than in the controls, and, again, Treg frequencies were equal to the healthy controls (Figure 2).

The differences between anti-TNF-responders and non-responders included significantly lower percentages of total CD4, and higher proportion of CD4HLA-DR T-cells in anti-TNF responders than in anti-TNF non-responders. 
The impact long term IL6-receptor blocker therapy on the immunophenotype of RA patients

Comparing effective IL6R-blocker-treated and early, active, therapy-naïve RA patients, low number of CD8 cells, and the higher prevalence of Th17 and Treg cells in the IL6-R blocker subgroup are the most important differences. Naive T-cell (both CD4 and CD8) and CD8 memory cell proportions were lower in anti-IL6-R-treated RA patients (Figures 1 and 2). Some further differences can also be observed when comparing with healthy controls: higher prevalence of Th2 cells, of CD4HLA-DR and CD8CD69 activated T-cells in patients on tocilizumab.

Anti-IL6-R-responders differ from anti-TNF-responders in significantly higher CD4 and lower CD8 T-cell frequencies (Figure 1). Anti-IL6-R-responders had the lowest proportion of Th1 cells in all the examined groups, and this difference was significant from both anti-TNFresponders and anti-TNF-non-responders (Figure 2). On the contrary, the proportions of Th2 and Th17 cells were higher among anti-IL6-R-responders, than in anti-TNF-treated RA patients independent of the responder state. Importantly, similarly to anti-TNF-treated groups, Treg frequencies were normal (Figure 2). With regards to the activated T-cell subsets, anti-IL6-Rtherapy was associated with higher percentages of CD69 T-cells, within both the CD4 and the CD8 subsets, than anti-TNF therapy, and CD4CD25 cells were also more prevalent than in antiTNF-responders (Figure 1).

Time-course of the changes in the T-cell subset distribution in RA patients on longstanding anti-TNF therapy

We compared the T-cell subset proportion values from the beginning of the disease in 13 patients (7 anti-TNF-responders and 6 anti-TNF-non-responders). As compared with the baseline values (at disease onset, before anti-TNF therapy initiation), percentages of total CD4 T-cells, CD4 and CD8 naive T-cells decreased (Figure 3), but those of Tregs increased over time in both anti-TNF-responders and anti-TNF-non-responders (Figure 4). Th1 and Th17 proportion increased only in the anti-TNF-responder group, and Th2 cell frequencies increased only within the anti-TNF-non-responders (Figure 4). CD4CD69 cell proportion decreased in the anti-TNF-non-responders $(\mathrm{p}<0.05$ with ANOVA, but no significant differences with Bonferroni's correction), and CD4HLA-DR cell percentages increased only in the anti-TNF- 
responders (Figure 4). Among CD8 cells, memory T-cells became less prevalent during the course of the disease only in the anti-TNF-non-responders, while HLA-DR activated cell frequency was gradually rising in the anti-TNF-responder group only. As it can be seen in Figure 3 and 4, most of these changes have become evident only after long-term follow-up.
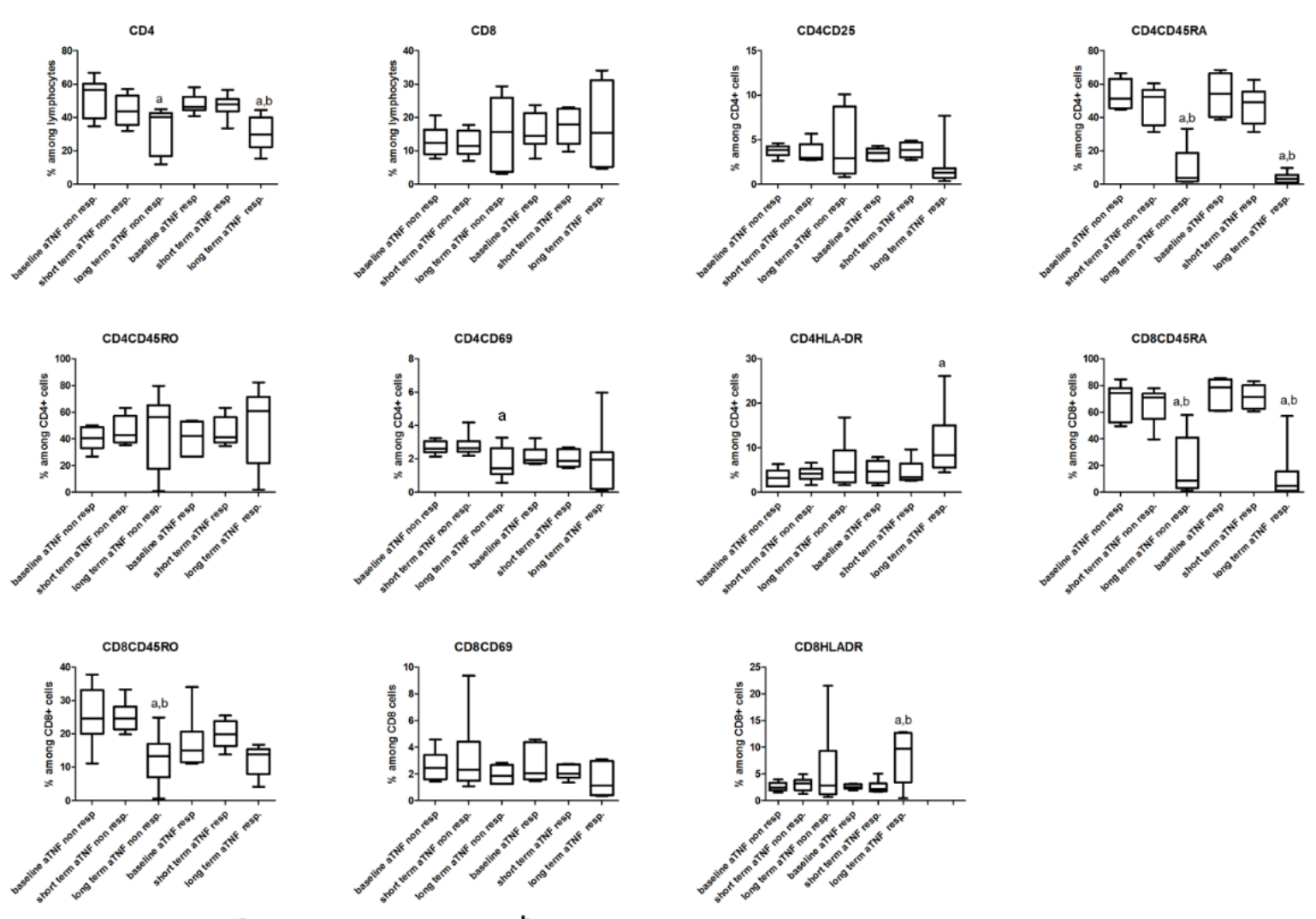

${ }^{\mathrm{a}} \mathrm{p}<0.05$ vs baseline, ${ }^{\mathrm{b}} \mathrm{p}<0.05$ vs short term

Figure 3. Changes in the proportions of T-cell subsets in RA patients in whom long-term followup data from the initiation of anti-TNF therapy were available $(n=13)$.

Seven patients from the initial short-term cohort (26) proved to be long-term responders, whereas the other 6 patients lost the initial response, and therefore became part of the nonresponder group. Measurement time-points: baseline: at anti-TNF initiation, short term: 8 weeks of anti-TNF treatment (previously published data (26)), long-term: current measurement results after long-standing anti-TNF treatment. Data are presented as median (horizontal line within boxes), 25 and 75 percentile (horizontal borders of the boxes), and minimum and maximum (whiskers). a $p<0.05$ vs baseline, $b p<0.05$ vs short term 

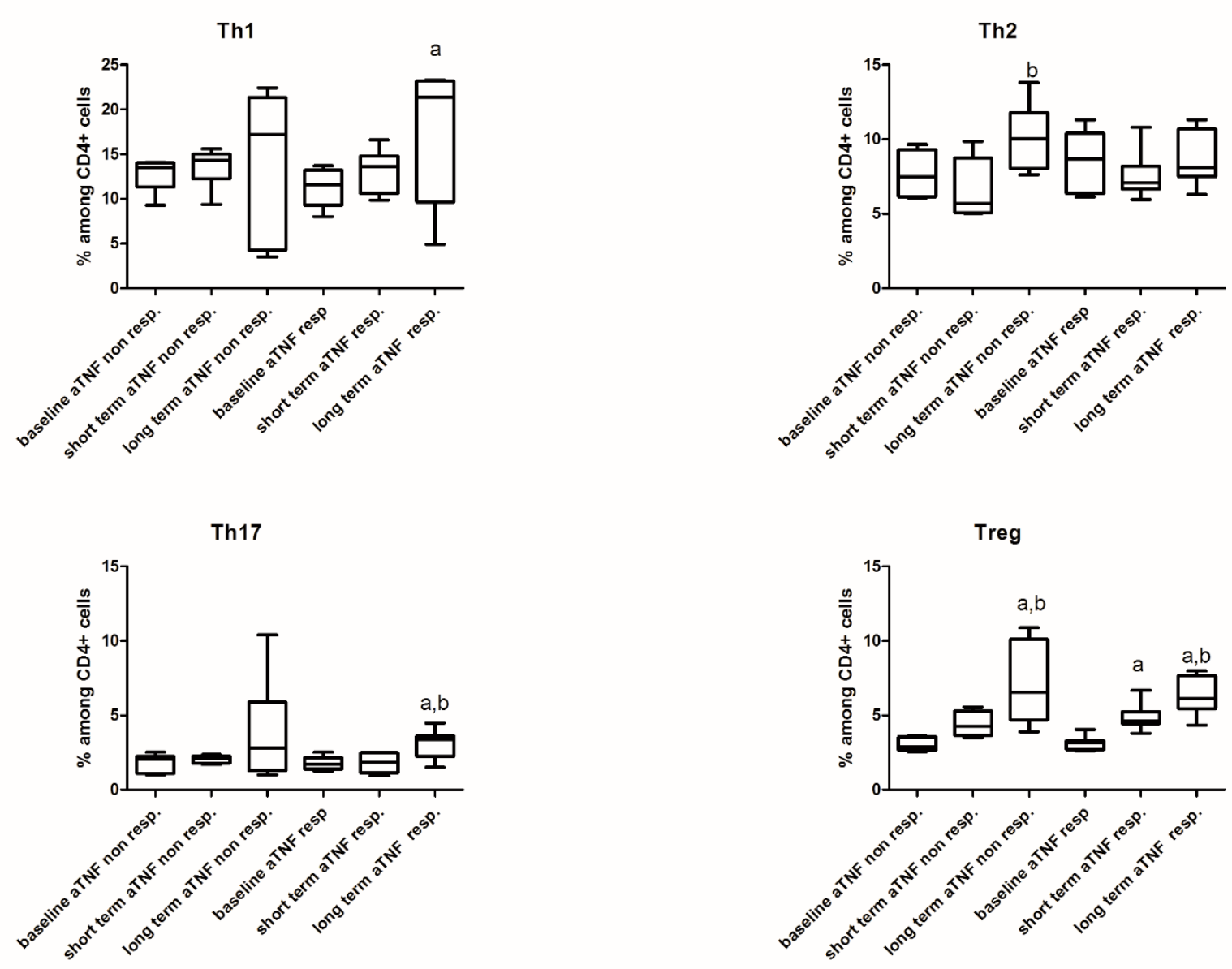

${ }^{a} p<0.05$ vs baseline, ${ }^{b} p<0.05$ vs short term

Figure 4. Changes in the proportions of the major effector T-helper cell subsets in RA patients in whom long-term follow-up data from the initiation of anti-TNF therapy were available $(n=$ $13)$.

Seven patients from the initial short-term cohort (26) proved to be long-term responders, whereas the other 6 patients lost the initial response, and therefore became part of the nonresponder group. Measurement time-points: baseline: at anti-TNF initiation, short term: 8 weeks of anti-TNF treatment (previously published data (26)), long-term: current measurement results after long-standing anti-TNF treatment. Data are presented as median (horizontal line within boxes), 25 and 75 percentile (horizontal borders of the boxes), and minimum and maximum (whiskers). a $p<0.05$ vs baseline, $b p<0.05$ vs short term 
The connection of the length of biological therapy on T-cell subset proportions in longterm treated RA patients

Since the duration of biological therapies was highly variable among long-term treated RA patients (ranging from 6 to 52 months) the question may arise whether this wide time-span could have an impact on the long-term effects of biologicals on the T-cell composition. We therefore further stratified the patients according to the duration of long-term biological therapy to "short" (6-12 months), "medium" (12-18 months) and "long" (> 18 months) duration of treatment. Comparison among these subgroups has revealed that only two of the examined 15 T-cell subtypes displayed a significant variability across these three subgroups: the prevalences of CD4+CD45RA+ and CD8+CD45RA+ naive cells decrease gradually among the three subgroups with longer treatment duration, and reaches a significance of $p<0.05$ in the comparison between „long” long-term duration vs the other two subgroups. All the other parameters have remained stable irrespective of the length of biological therapy (Table 5). 


\begin{tabular}{|c|c|c|c|c|c|c|c|c|c|c|c|c|c|c|c|c|c|}
\hline & & & CD4 & $\begin{array}{c}\text { CD4/ } \\
\text { CD45 } \\
\text { RA }\end{array}$ & $\begin{array}{c}\text { CD4/ } \\
\text { CD45 } \\
\text { RO }\end{array}$ & $\begin{array}{l}\text { CD4/ } \\
\text { CD69 }\end{array}$ & $\begin{array}{c}\text { CD4/ } \\
\text { HLA } \\
\text { DR }\end{array}$ & $\begin{array}{l}\text { CD4/ } \\
\text { CD25 }\end{array}$ & CD8 & $\begin{array}{c}\text { CD8/ } \\
\text { CD45 } \\
\text { RA }\end{array}$ & $\begin{array}{c}\text { CD8/ } \\
\text { CD45 } \\
\text { RO }\end{array}$ & $\begin{array}{c}\text { CD8/ } \\
\text { HLA } \\
\text { DR }\end{array}$ & $\begin{array}{l}\text { CD8/ } \\
\text { CD69 }\end{array}$ & Th1 & Th2 & Th17 & Treg \\
\hline \multirow{9}{*}{ 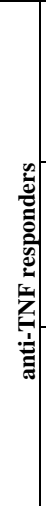 } & \multirow{3}{*}{$\frac{5}{5}$} & I & 25,35 & 4,60 & $46,95^{a}$ & 1,95 & 8,03 & 1,00 & 9,18 & $4,68^{a}$ & 5,97 & 2,90 & 0,57 & 18,2 & 7,51 & 2,49 & 4,68 \\
\hline & & II & 32,45 & 7,73 & 60,32 & 2,74 & 9,132 & 1,62 & 19,45 & 46,7 & 18,1 & 10,51 & 2,5 & 23,15 & 9,02 & 3,347 & 6,82 \\
\hline & & III & 25,35 & 4,60 & 46,95 & 1,94 & 8,02 & 1,00 & 9,18 & 4,68 & 5,97 & 2,90 & 0,57 & 18,2 & 7,51 & 2,49 & 4,67 \\
\hline & \multirow{3}{*}{ : } & I & 31,25 & 8,13 & $49,25^{\mathrm{a}}$ & 1,92 & 5,58 & 1,16 & 13,05 & $14,1^{\mathrm{a}}$ & 15,25 & 4,01 & 1,10 & 20,7 & 7,76 & 2,9 & 5,57 \\
\hline & & II & 26,65 & 4,06 & 45,45 & 1,32 & 5,36 & 0,88 & 10,29 & 5,67 & 12,22 & 1,837 & 0,63 & 18,8 & 7,17 & 2,56 & 4,88 \\
\hline & & III & 36,77 & 10,56 & 66,82 & 2,69 & 7,89 & 1,24 & 16,07 & 31,45 & 17,95 & 5,96 & 1,62 & 23,47 & 10,05 & 3,35 & 6,11 \\
\hline & \multirow{3}{*}{ 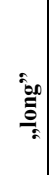 } & I & 22,2 & 1,79 & 37,3 & 0,845 & 6,02 & 1,10 & 8,57 & 3,97 & 10,85 & 6,82 & 0,78 & 19,9 & 8,06 & 2,38 & 6,43 \\
\hline & & II & 16,7 & 1,28 & 13,69 & 0,232 & 4,35 & 0,51 & 4,63 & 1,07 & 4,357 & 3,027 & 0,49 & 16,65 & 6,99 & 2,17 & 4,3 \\
\hline & & III & 32,87 & 2,91 & 56 & 2,597 & 12,57 & 1,77 & 17,97 & 6,32 & 14,2 & 9,74 & 1,09 & 23,77 & 9,00 & 3,04 & 6,86 \\
\hline \multirow{6}{*}{ 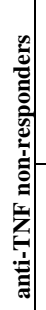 } & \multirow{3}{*}{$\frac{\hat{t}}{5}$} & I & 41 & 3,49 & 53,2 & 1,07 & 5,89 & 1,59 & 9,54 & 2,08 & 5,72 & 5,41 & 0,61 & 18,7 & 7,96 & 4,93 & 4,44 \\
\hline & & II & 30,9 & 3,24 & 26,8 & 1,03 & 3,78 & 0,97 & 7,62 & 1,55 & 3,16 & 2,82 & 0,58 & 12,79 & 7,51 & 2,85 & 4,32 \\
\hline & & III & 41,3 & 10,99 & 57,85 & 3,02 & 7,255 & 5,52 & 18,87 & 11,69 & 16,11 & 9,35 & 0,62 & 20,45 & 11,23 & 5,12 & 5,70 \\
\hline & \multirow{3}{*}{$\begin{array}{l}0.0 \\
\vdots \\
\vdots \\
\vdots\end{array}$} & I & 40,15 & 4,52 & 55,7 & 1,37 & 4,20 & 2,32 & 13,35 & 7,45 & 11,19 & 4,07 & 1,36 & 18,25 & 8,7 & 2,71 & 5,86 \\
\hline & & $\begin{array}{l}\text { II } \\
\end{array}$ & 25,62 & 2,47 & 22,92 & 1,15 & 2,6 & 1,16 & 6,33 & 2,40 & 6,86 & 1,33 & 1,05 & 11,92 & 6,65 & 1,45 & 5,44 \\
\hline & & III & 44,92 & 13,17 & 62,67 & 2,63 & 6,28 & 5,64 & 20,57 & 36,12 & 14,87 & 4,67 & 2,07 & 21,5 & 11,1 & 4,20 & 7,81 \\
\hline \multirow{9}{*}{ 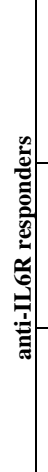 } & \multirow{3}{*}{ 豙 } & I & 31,7 & 3,96 & 28,7 & 5,19 & 4,17 & 4,28 & 5,79 & 3,47 & 8,52 & 2,88 & 3,68 & 4,83 & 13,0 & 5,19 & 4,69 \\
\hline & & II & 25,3 & 1,81 & 17,7 & 1,85 & 2,52 & 1,5 & 3,73 & 1,71 & 7,37 & 1,46 & 1,76 & 3,4 & 9,31 & 3,09 & 4,01 \\
\hline & & III & 42,4 & 8,03 & 42,7 & 8,1 & 5,83 & 4,78 & 6,96 & 9,96 & 15,2 & 4,23 & 11,5 & 13,6 & 14,3 & 6,19 & 5,83 \\
\hline & \multirow{3}{*}{ : } & I & 27,05 & 3,21 & 47,75 & 3,63 & 5,65 & 4,30 & 5,41 & 4,54 & 9,7 & 2,92 & 6,96 & 7,41 & 11,26 & 4,69 & 4,75 \\
\hline & & II & 25,77 & 2,51 & 6,415 & 1,34 & 3,51 & 1,076 & 4,04 & 2,89 & 8,15 & 1,605 & 3,37 & 3,44 & 6,74 & 3,27 & 4,59 \\
\hline & & III & 36,25 & 10,04 & 64,6 & 6,4 & 10,47 & 6,02 & 8,82 & 32,48 & 12,3 & 8,21 & 10,29 & 17,82 & 16,4 & 5,38 & 5,0 \\
\hline & \multirow{3}{*}{$\begin{array}{l}600 \\
\overline{0} \\
\bar{E}\end{array}$} & I & 41,35 & 2,89 & 43,35 & 4,10 & 5,38 & 4,71 & 5,53 & 5,83 & 11,7 & 2,81 & 3,99 & 5,2 & 11,9 & 4,96 & 4,63 \\
\hline & & II & 34,82 & 1,21 & 10,96 & 2,01 & 4,48 & 1,63 & 4,14 & 2,51 & 8,17 & 2,01 & 2,81 & 3,03 & 9,99 & 4,41 & 4,05 \\
\hline & & III & 49,07 & 4,865 & 51,02 & 9,29 & 7,395 & 5,34 & 7,68 & 39,12 & 14,27 & 4,50 & 12,35 & 8,76 & 13,4 & 5,42 & 6,31 \\
\hline
\end{tabular}

Table 5. Subgroup analysis in the long-term treated RA patient groups according to the length of the biologic therapy.

Numbers indicate the median percentages and $25 \%$ and $75 \%$ percentile values within the whole T-cell population (CD4 and CD8 cells), or within CD4 cells (Th1, Th2, Th17, Treg and ratios), or for the other markers within the CD4 or CD8 cells, as indicated. I: median, II: $25^{\text {th }}$ percentile, III: $75^{\text {th }}$ percentile, ${ }^{a} p<0.05$ vs anti-TNF responders ,,long” long-term 
The impact of previous switching of anti-TNF agents on T-cell subsets

In some patients (especially in the IL6-R blocker-treated group) the biological agent applied at the time of sampling was not the first one, but there were previous switches from other anti-TNF drugs (Table 1). Although these switches were made more than 6 months before the blood sampling, we wanted to know whether the previous changes in therapy may have influenced the T-cell phenotype. We therefore compared the patient subgroups as defined by the number of previous switches in all therapeutic groups (Table 6). This analysis revealed that the proportions of CD4CD69 and of CD8CD69 cells were higher in IL6-R-responder patients who had experienced three switches before the current therapy than in those who had only one switch before (Figure 5). Opposite difference was observed with regard to Th1 percentage. 


\begin{tabular}{|c|c|c|c|c|c|c|c|c|c|c|c|c|c|c|c|c|c|}
\hline & & & CD4 & $\begin{array}{l}\text { CD4 } \\
\text { CD45 } \\
\text { RA }\end{array}$ & $\begin{array}{l}\text { CD4 } \\
\text { CD45 } \\
\text { RO }\end{array}$ & $\begin{array}{l}\text { CD4 } \\
\text { CD69 }\end{array}$ & $\begin{array}{l}\text { CD4 } \\
\text { HLA } \\
\text { DR }\end{array}$ & $\begin{array}{l}\text { CD4 } \\
\text { CD25 }\end{array}$ & CD8 & $\begin{array}{l}\text { CD8 } \\
\text { CD45 } \\
\text { RA }\end{array}$ & $\begin{array}{l}\text { CD8 } \\
\text { CD45 } \\
\text { RO }\end{array}$ & $\begin{array}{l}\text { CD8 } \\
\text { HLA } \\
\text { DR }\end{array}$ & $\begin{array}{l}\text { CD8 } \\
\text { CD69 }\end{array}$ & Th1 & Th2 & Th17 & Treg \\
\hline \multirow{6}{*}{ 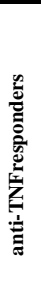 } & \multirow{3}{*}{ 竞 } & I & 33,4 & 14,1 & 40,3 & 1,47 & 5,36 & 0,96 & 14,2 & 20,2 & 14,1 & 5,51 & 0,96 & 16,7 & 8,95 & 2,67 & 6,84 \\
\hline & & II & 33,05 & 8,08 & 40,1 & 1,145 & 4,575 & 0,695 & 12,4 & 12,18 & 9,265 & 4,07 & 0,575 & 15,95 & 8,36 & 2,305 & 5,515 \\
\hline & & III & 41,75 & 18,55 & 44,8 & 2,02 & 5,44 & 1,21 & 16,5 & 25,6 & 15,25 & 5,755 & 1,49 & 17,55 & 9,47 & 2,92 & 6,87 \\
\hline & \multirow{3}{*}{ 主 } & I & 24,4 & 3,17 & 47,3 & 1,8 & 7,92 & 1,2 & 9,77 & 5,41 & 12,6 & 6,19 & 0,86 & 21,7 & 8,02 & 2,82 & 5,85 \\
\hline & & II & 17,25 & 1,505 & 19,65 & 0,46 & 4,49 & 0,58 & 5,34 & 2,19 & 5,60 & 2,89 & 0,48 & 17,2 & 7,13 & 2,25 & 4,44 \\
\hline & & III & 33,15 & 7,77 & 64,8 & 2,91 & 9,84 & 1,57 & 19,25 & 15,5 & 17,2 & 9,74 & 2,09 & 23,85 & 9,24 & 3,30 & 6,63 \\
\hline \multirow{6}{*}{ 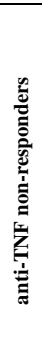 } & \multirow{3}{*}{ 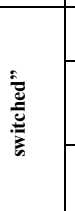 } & I & 30,15 & 2,77 & 38,55 & 1,425 & 3,59 & 1,54 & 24,75 & 8,55 & 11,02 & 2,86 & 1,85 & 20,9 & 8,81 & 1,4 & 7,09 \\
\hline & & II & 19,07 & 2,11 & 6,30 & 1,28 & 1,85 & 0,94 & 11,11 & 2,21 & 2,77 & 0,96 & 1,31 & 15,4 & 8,02 & 1,11 & 6,19 \\
\hline & & III & 41,37 & 11,25 & 58,7 & 2,21 & 6,38 & 3,53 & 27,35 & 29,35 & 13,58 & 4,95 & 2,53 & 21,9 & 10,31 & 3,48 & 9,19 \\
\hline & \multirow{3}{*}{ 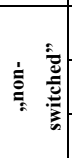 } & I & 41 & 4,92 & 57,5 & 1,25 & 4,33 & 2,94 & 9,96 & 7,18 & 9,48 & 4,31 & 1,05 & 18,1 & 7,07 & 4,11 & 5,65 \\
\hline & & II & 29,8 & 3,49 & 49,8 & 1,07 & 2,69 & 1,19 & 6 & 2,17 & 5,72 & 1,38 & 0,535 & 6,9 & 6,39 & 2,08 & 4,64 \\
\hline & & III & 45 & 12,9 & 62,5 & 2,7 & 6,08 & 6,39 & 17,3 & 33,8 & 15,4 & 5,41 & 1,49 & 21,5 & 12,9 & 4,4 & 6,14 \\
\hline \multirow{12}{*}{ 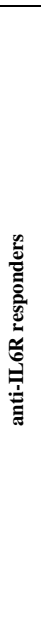 } & \multirow{3}{*}{ 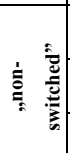 } & I & 41,4 & 1,88 & 40 & 5,51 & 5,35 & 4,5 & 6,13 & 4,96 & 11,5 & 2,15 & 5,09 & 3,9 & 12,8 & 5,2 & 4,85 \\
\hline & & II & 31,3 & 1,345 & 21,2 & 3,405 & 3,43 & 2,35 & 4,72 & 2,39 & 8,49 & 1,47 & 2,96 & 3,005 & 9,93 & 4,38 & 4,12 \\
\hline & & III & 52,25 & 7,79 & 58,1 & 12,77 & 7,625 & 5,5 & 7,54 & 37,95 & 15,2 & 3,41 & 12,7 & 7,675 & 14,55 & 5,815 & 5,98 \\
\hline & \multirow{3}{*}{ 总 } & I & 25,7 & 5,435 & 28,7 & 1,44 & 5,55 & 1,5 & 7,54 & 3,37 & 8,2 & 4,23 & 2,45 & 16 & 10,7 & 3,95 & 4,69 \\
\hline & & II & 22,9 & $\begin{array}{ll}1,60 \\
\end{array}$ & 9,04 & 0,78 & 3,98 & 0,66 & 3,87 & 1,87 & 5,975 & 2,30 & 0,92 & 6,12 & 7,35 & 3,07 & 4,39 \\
\hline & & III & 33,65 & 10,05 & 43,45 & 1,85 & 7,16 & 3,94 & 10,24 & 33,9 & 11,75 & 5,68 & 5,24 & 17,85 & 12,2 & 4,895 & 6,17 \\
\hline & \multirow{3}{*}{ 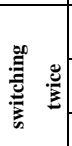 } & I & 35,4 & 4,12 & 12,5 & 4,6 & 5,83 & 5,14 & 6,36 & 6,64 & 12,5 & 4,28 & 4,11 & 5,65 & 13,3 & 5,41 & 4,45 \\
\hline & & II & 26,6 & 3,02 & 10,7 & 3,13 & 5,77 & 2,47 & 4,17 & 2,47 & 10,7 & 2,88 & 3,12 & 4,92 & 7,85 & 3,73 & 4,21 \\
\hline & & III & 48,9 & 10,6 & 13,3 & 10,6 & 8,88 & 6,57 & 9,65 & 37,7 & 13,3 & 9,37 & 9,97 & 17,3 & 15,8 & 6,45 & 4,75 \\
\hline & \multirow{3}{*}{ 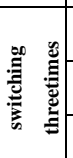 } & I & 34,3 & 2,58 & 11,8 & $5,0^{\mathrm{a}}$ & 4,17 & 4,92 & 5,35 & 5,93 & 10,5 & 2,29 & $10,4^{\mathrm{a}}$ & 3 & 12,7 & 5,07 & 4,81 \\
\hline & & II & 27,5 & 2,38 & 3,29 & 4,14 & 3,11 & 4,78 & 5,02 & 5,63 & 6,46 & 1,98 & 5,04 & 2,72 & 12,5 & 5,01 & 3,82 \\
\hline & & III & 42,4 & 2,89 & 50 & 15,8 & 4,68 & 5,35 & 5,74 & 9,96 & 14,8 & 3,8 & 16,3 & 4,33 & 13 & 5,3 & 5,06 \\
\hline
\end{tabular}

Table 6. Subgroup analysis of cell prevalences according to the number of previous switches

Numbers indicate values within the whole T-cell population (CD4 and CD8 cells), or within CD4 cells (Th1, Th2, Th17, Treg), or for the other markers within the CD4 or CD8 cells, as indicated. I: median, II: $25^{\text {th }}$ percentile, III: $75^{\text {th }}$ percentile. ${ }^{a} p<0.05$ vs anti-IL6R responders, switching once 

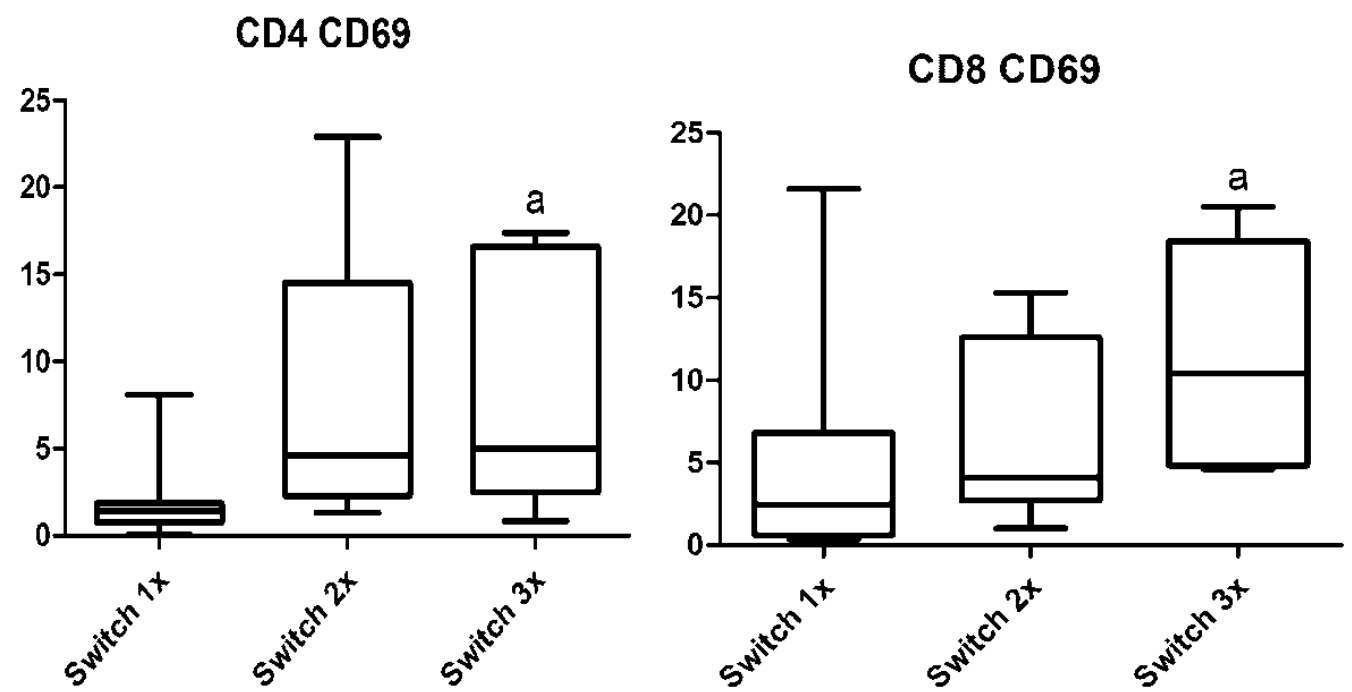

Figure 5. The frequencies of CD4CD69 and of CD8CD69 cells in anti-IL6-R-responder RA patients grouped according to the number of previous switches in anti-TNF therapy before the initiation of the present tocilizumab treatment.

Numbers indicate percentages within the CD4 or CD8 T-cells, as applicable. ${ }^{a} p<0.05$ vs $1 x$ switch.

Differences among the various anti-TNF agents

When we compared the T-cell subset proportions among the 5 anti-TNF agents individually (including adalimumab, etanercept, certolizumab, golimumab, infliximab) and between the particular anti-TNF drugs and anti-Il-6R-responders or healthy controls, only one significant difference was revealed in addition to the comparisons when the anti-TNF drugs were considered as one single group: the frequencies of CD4CD45RO cells were higher among etanercept-treated patients (responders and non-responders taken together) than among IL-6Rblocker-responders. The effect of the various anti-TNF agents on the immunophenotype of the RA-patients was not different (Table 7). 


\begin{tabular}{|c|c|c|c|c|c|c|c|c|c|c|c|c|c|c|c|c|}
\hline & & CD4 & $\begin{array}{l}\text { CD4/ } \\
\text { CD45 } \\
\text { RA }\end{array}$ & $\begin{array}{l}\text { CD4/ } \\
\text { CD45 } \\
\text { RO }\end{array}$ & $\begin{array}{l}\text { CD4/ } \\
\text { CD69 }\end{array}$ & $\begin{array}{l}\text { CD4/ } \\
\text { HLA } \\
\text { DR }\end{array}$ & CD8 & $\begin{array}{l}\text { CD8/ } \\
\text { CD45 } \\
\text { RA }\end{array}$ & $\begin{array}{l}\text { CD8/ } \\
\text { CD45 } \\
\text { RO }\end{array}$ & $\begin{array}{l}\text { CD8/ } \\
\text { HLA } \\
\text { DR }\end{array}$ & $\begin{array}{l}\text { CD8/ } \\
\text { CD69 }\end{array}$ & $\begin{array}{l}\text { CD4/ } \\
\text { CD25 }\end{array}$ & Th1 & Th2 & Th17 & Treg \\
\hline \multirow{3}{*}{ 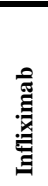 } & I & 37.2 & 5.11 & 43.8 & 2.57 & 4.57 & 14.3 & 6.09 & 5.25 & 4.94 & 0.72 & 0.76 & 8.97 & 7.17 & 2.47 & 5.81 \\
\hline & II & 26.5 & 1.83 & 22.0 & 0.85 & 3.18 & 8.89 & 1.98 & 4.21 & 3.65 & 1.00 & 0.97 & 18.4 & 8.22 & 1.83 & 4.59 \\
\hline & III & 47.2 & 8.74 & 50.2 & 5.22 & 6.76 & 19.5 & 19.8 & 12.2 & 6.96 & 1.90 & 3.21 & 19.5 & 10.5 & 4.23 & 7.12 \\
\hline \multirow{3}{*}{ 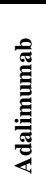 } & I & 29.4 & 3.24 & 51.1 & 1.50 & 6.02 & 14.1 & 4.78 & 11.3 & 5.20 & 0.46 & 0.50 & 16.6 & 7.34 & 3.01 & 5.66 \\
\hline & II & 16.7 & 2.07 & 30.0 & 0.85 & 3.86 & 5.67 & 1.60 & 5.01 & 1.66 & 0.88 & 1.01 & 21.0 & 8.24 & 2.25 & 4.27 \\
\hline & III & 37.0 & 10.4 & 62.3 & 2.37 & 10.0 & 23.5 & 6.44 & 15.7 & 9.78 & 1.75 & 2.07 & 23.4 & 9.72 & 4.17 & 7.31 \\
\hline \multirow{3}{*}{ 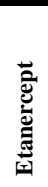 } & I & 32.7 & 4.20 & 67.2 & 1.88 & 7.86 & 9.36 & 11.8 & 13.8 & 6.19 & 0.68 & 1.19 & 5.25 & 6.34 & 3.29 & 4.96 \\
\hline & II & 22.6 & 1.79 & 53.7 & 0.57 & 4.45 & 4.44 & 3.77 & 9.30 & 1.82 & 1.16 & 1.69 & 21.0 & 8.19 & 1.82 & 3.89 \\
\hline & III & 40.1 & 7.75 & 77.1 & 3.04 & 13.3 & 24.8 & 36.3 & 21.9 & 10.6 & 1.42 & 5.49 & 23.0 & 11.3 & 3.98 & 5.93 \\
\hline \multirow{3}{*}{ 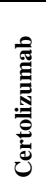 } & I & 27.3 & 4.91 & 39.3 & 1.20 & 4.91 & 12.3 & 9.11 & 10.9 & 3.36 & 0.48 & 1.18 & 16.9 & 6.79 & 2.31 & 6.60 \\
\hline & II & 16.3 & 2.04 & 0.79 & 0.57 & 1.61 & 7.19 & 1.16 & 0.89 & 1.05 & 2.04 & 1.50 & 19.7 & 8.03 & 1.40 & 5.64 \\
\hline & III & 44.9 & 17.0 & 62.2 & 2.78 & 8.81 & 20 & 39.8 & 19.8 & 6.53 & 2.68 & 3.39 & 22.2 & 9.60 & 3.45 & 8.26 \\
\hline \multirow{3}{*}{ 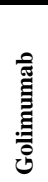 } & I & 24.1 & 2.64 & 35.5 & 0.83 & 5.72 & 6.76 & 6.29 & 14.3 & 7.14 & 0.23 & 0.58 & 16.8 & 6.00 & 2.66 & 6.76 \\
\hline & II & 18.7 & 0.62 & 5.71 & 0.16 & 4.65 & 2.12 & 1.72 & 3.79 & 3.91 & 0.68 & 1.12 & 23.5 & 6.68 & 1.67 & 6.01 \\
\hline & III & 44.1 & 11.6 & 55.4 & 2.29 & 9.32 & 12.4 & 16.9 & 16.1 & 14.8 & 1.71 & 1.44 & 30.5 & 9.29 & 3.15 & 6.92 \\
\hline
\end{tabular}

Table 7. Prevalence values of the various T-cell subsets according to different anti-TNF therapies

Numbers indicate values within the whole T-cell population (CD4 and CD8 cells), or within CD4 cells (Th1, Th2, Th17, Treg and ratios), or for the other markers within the CD4 or CD8 cells, as indicated. . I: median, II: $25^{\text {th }}$ percentile, III: $75^{\text {th }}$ percentile. 
Relationship between baseline T-cell subset prevalences and response to therapy

Through the analysis of the prospective follow-up cohort, in which we compared the T-cell subset frequencies at baseline (i.e. at the start of the anti-TNF therapy), short-term (8 weeks) and long term therapy, we examined whether any baseline parameters are predictive of the longterm response to anti-TNF therapy. The proportion of CD4CD69 T-cells at baseline $(2.16 \pm 0.12$ vs $2.69 \pm 0.16, \mathrm{p}=0.08)$ and at 8 weeks $(2.01 \pm 0.20$ vs $2.81 \pm 0.28, \mathrm{p}=0.03)$ was lower in those who later belonged to anti-TNF-responders than in those who became anti-TNF-non-responders. ROC analysis revealed that a CD4CD69 T-cell percentage $<2.43$ at baseline predicts a future response to anti-TNF therapy with a likelihood ratio of 4.29 (CI: 0.58-1.06), and discriminates between future anti-TNF-responders and non-responders with a sensitivity of $71.4 \%$ and a specificity of $83.3 \%(\mathrm{p}=0.054)$ (Figure 6).

\section{ROC of CD4CD69:ROC curve}

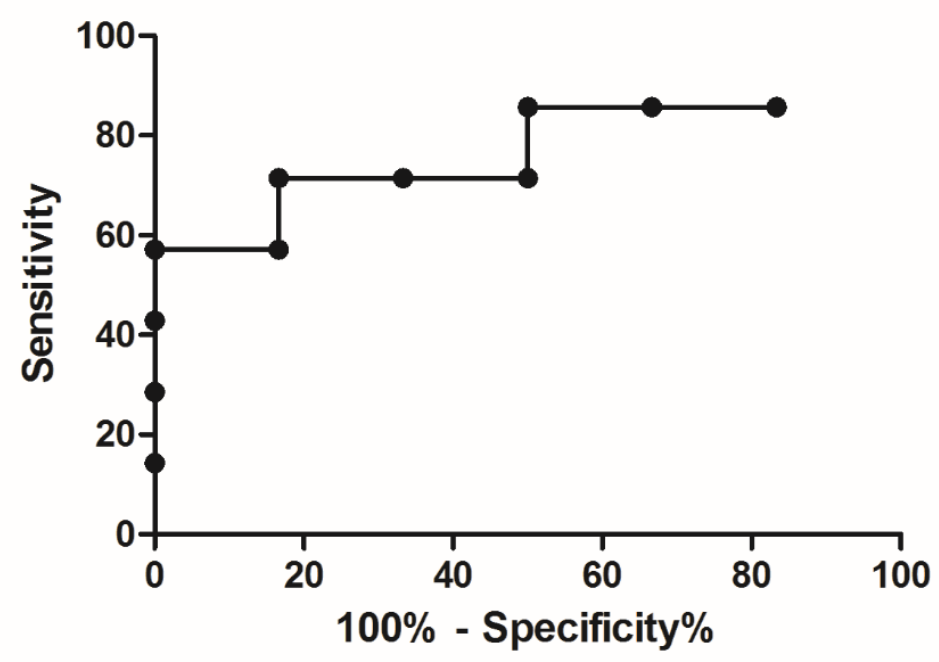

Figure 6. Receiver-operator characteristic (ROC) curve of CD4CD69 positivity.

Predictive potential of the percentage of CD4CD69 positive cells at baseline (start of anti-TNF) to long-term response to therapy. CD4CD69 T-cell percentage $<2.43$ has the highest likelihood ratio (4.29 [CI: 0.58-1.06] to discriminate between future anti-TNF-responders and nonresponders (sensitivity: $71.4 \%$, specificity: $83.3 \%, p=0.054$ ). 


\subsection{Ankylosing spondylitis}

\subsubsection{T-cell repertoire composition of AS patients on long-term anti-TNF therapy}

T-cell phenotypes of AS patients on long-term anti-TNF therapies are presented in Figures 7 and 8, and numerically in Table 8. All anti-TNF-treated AS patients (both anti-TNF non-responders and anti-TNF responders) show a significantly lower prevalence of naive CD4 and CD8 cells (CD4CD45RA and CD8CD45RA), and higher frequencies of Th1 and Th17 cells, and Th17/Treg ratios than healthy controls. Treg proportion was similar to that in healthy subjects. The prevalence of T-cells with the late activation marker (CD4HLADR and CD8HLADR) was higher, and of T-cells with the intermediate activation marker (CD4CD25) was lower, and the Th1/Th2 ratio was higher only in the anti-TNF responders than in the controls. Differences between the two AS patients groups are as follows: in anti-TNF responders, the frequencies of naive CD4 and CD8 cells (CD4CD45RA and CD8CD45RA), and of early activated CD8CD69 cells were lower than in anti-TNF non-responders. 


\begin{tabular}{|c|c|c|c|}
\hline & $\begin{array}{l}\text { anti-TNF non-responders } \\
\qquad(\mathrm{n}=7)\end{array}$ & $\begin{array}{c}\text { anti-TNF responders } \\
(\mathrm{n}=15)\end{array}$ & $\begin{array}{c}\text { controls } \\
(n=10)\end{array}$ \\
\hline CD4 & $39,39 \pm 16,02$ & $30,02 \pm 17,23$ & $40,56 \pm 7,835$ \\
\hline CD8 & $16,59 \pm 13,73$ & $16,631 \pm 2,64$ & $22,56 \pm 8,073$ \\
\hline CD4CD45RA & $21,40 \pm 16,50$ & $6,484 \pm 5,213^{a}$ & $56,761 \pm 0,34^{\mathrm{a}, \mathrm{b}}$ \\
\hline CD4CD45RO & $52,041 \pm 8,71$ & $49,87 \pm 27,97$ & $36,49 \pm 10,05$ \\
\hline CD4CD69 & $1,800 \pm 0,6677$ & $2,159 \pm 2,514$ & $2,109 \pm 0,7517$ \\
\hline CD4CD25 & $3,791 \pm 2,766$ & $2,420 \pm 3,745$ & $7,444 \pm 0,8571^{b}$ \\
\hline CD4HLADR & $5,847 \pm 2,449$ & $14,33 \pm 14,34$ & $2,715 \pm 0,7444^{b}$ \\
\hline CD8CD45RA & $36,81 \pm 25,61$ & $15,16 \pm 18,93^{a}$ & $70,48 \pm 8,991^{a, b}$ \\
\hline CD8CD45RO & $21,66 \pm 5,943$ & $18,93 \pm 9,592$ & $22,31 \pm 7,879$ \\
\hline CD8CD69 & $10,55 \pm 11,12$ & $1,641 \pm 2,855^{a}$ & $1,578 \pm 0,5547$ \\
\hline CD8HLADR & $7,066 \pm 3,303$ & $10,41 \pm 7,445$ & $2,269 \pm 0,9214^{b}$ \\
\hline Th1 & $18,07 \pm 6,070$ & $21,39 \pm 6,452$ & $9,412 \pm 0,8024^{a, b}$ \\
\hline Th2 & $9,766 \pm 4,653$ & $8,206 \pm 1,326$ & $5,937 \pm 1,155^{a}$ \\
\hline Th1/Th2 & $2.435 \pm 1.526$ & $2.686 \pm 0.918$ & $1.656 \pm 0.437^{b}$ \\
\hline Th17 & $3,736 \pm 1,980$ & $3,144 \pm 1,066$ & $1,001 \pm 0,1746^{a, b}$ \\
\hline Treg & $5,996 \pm 2,131$ & $5,575 \pm 2,071$ & $5,715 \pm 0,7965$ \\
\hline Th17/Treg & $0.765 \pm 0.599$ & $0.697 \pm 0.685$ & $0.178 \pm 0.036^{a, b}$ \\
\hline
\end{tabular}

Table 8. Prevalence and ratios of T-cell subsets in long term anti-TNF treated AS patient groups and controls.

Numbers indicate mean $\pm S D$ values within the whole T-cell population (CD4 and CD8) or within CD4 cells (Th1, Th2, Th17, Treg and ratios), or for the other markers within the CD4 or CD8 cells, as indicated. ${ }^{a} p<0.05$ vs anti-TNF non-responder, ${ }^{b} p<0.05 v s$ anti-TNF responder. 
$\mathrm{CD} 4$

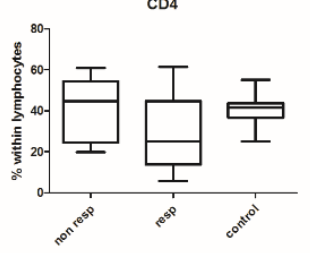

CD4CD69
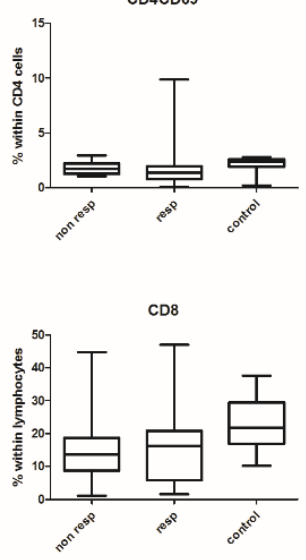

CD8CD69

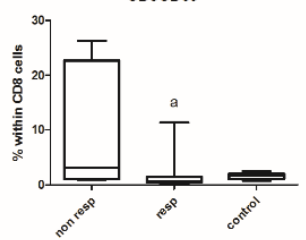

CD4CD45RA

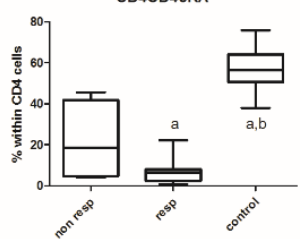

CD4HLADR

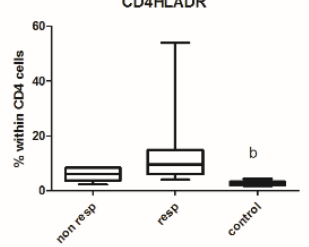

CD8CD45RA

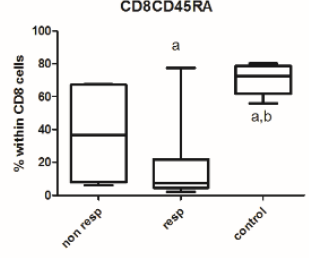

CD8HLADR

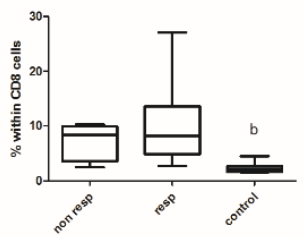

CD4CD45RO

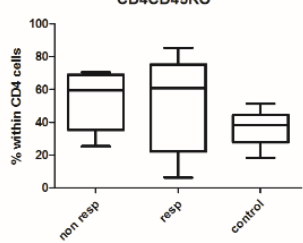

CD4CD25

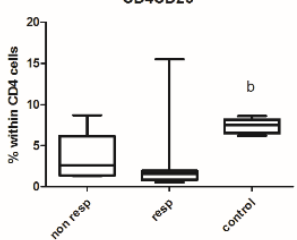

CD8CD45RO

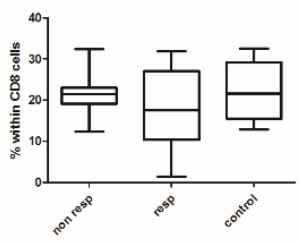

${ }^{a} p<0.05$ vs non-responder ${ }^{b} p<0.05$ vs responder

Figure 7. Proportions of various T-cell subsets in ankylosing spondylitis patient groups of longterm anti-TNF-responders $(n=15)$, long-term anti-TNF-non-responders $(n=7)$ and in healthy controls $(n=10)$.

Data are presented as median (horizontal line within boxes), 25 and 75 percentile (horizontal borders of the boxes), and minimum and maximum (whiskers). ${ }^{a} p<0.05$ vs anti-TNFnonresponder, ${ }^{b} p<0.05$ vs anti-TNFresponder, resp $=$ responder. 

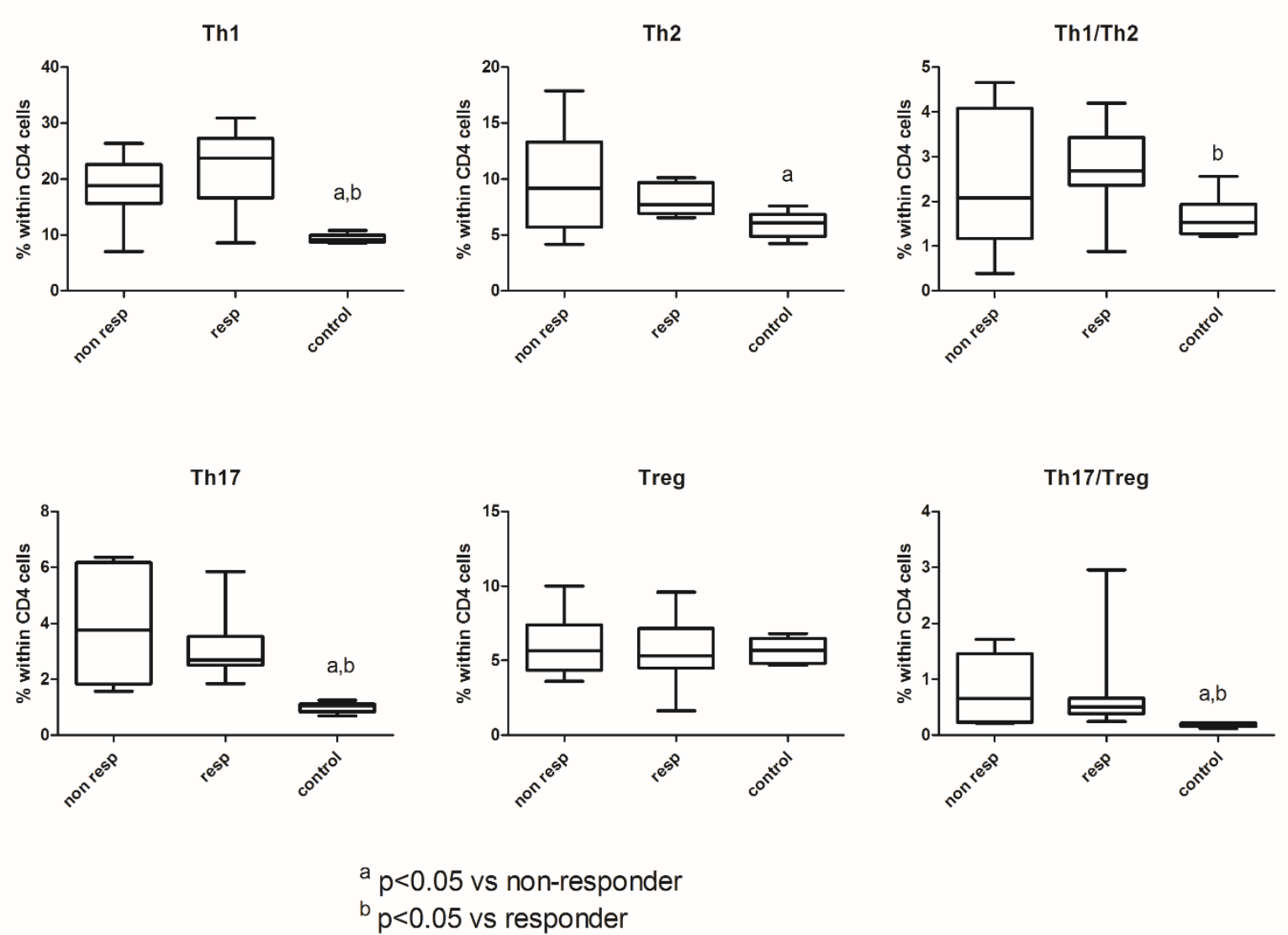

$$
\begin{aligned}
& \text { a } p<0.05 \text { vs non-responder } \\
& { }^{b} p<0.05 \text { vs responder }
\end{aligned}
$$

Figure 8. Proportions of the major effectorT-helper cell subsets in ankylosing spondylitis patient groups of long-term anti-TNF-responders $(n=15)$, long-term anti-TNF-nonresponders $(n=7)$ and in healthy controls $(n=10)$.

Data are presented as median (horizontal line within boxes), 25 and 75 percentile (horizontal borders of the boxes), and minimum and maximum (whiskers). ${ }^{a} p<0.05$ vs anti-TNFnonresponder, ${ }^{b} p<0.05$ vs anti-TNFresponder, resp $=$ responder.

4.2.2. Comparison of the T-cell phenotype of AS patients on long-term and short-term anti-TNF therapy

The database of early alterations in the T-cell repertoire in a cohort of anti-TNF-treated AS patients was available for us from our previous study (54), so we could compare these values with our present results. T-cell subset prevalence in AS patients at the time of the initiation of anti-TNF therapy, 2 and 6 weeks thereafter (short-term) and after long-term follow-up (at least 6 months after initiation of anti-TNF therapy) can be seen in Figures 9 and 10. In summary, the decrease in the proportion of naive CD4 and CD8 cells (CD4CD45RA and CD8CD45RA), and 
the increase in that of Th1, Th17 and Treg cells, and in Th1/Th2 ratios in the long-term antiTNF treated AS patients (responders, non-responders and total) has proven to be significant not only when compared with the controls (see above) but also with therapy-naive and short-term anti-TNF treated AS patients. Alterations within the various activated T-cell subsets including - increase in CD4HLADR-positive cells in responders, and in CD8HLADR and of CD4CD25 positive cells in the whole long term treated AS group and in responders - have also become evident only after long-term anti-TNF therapy.
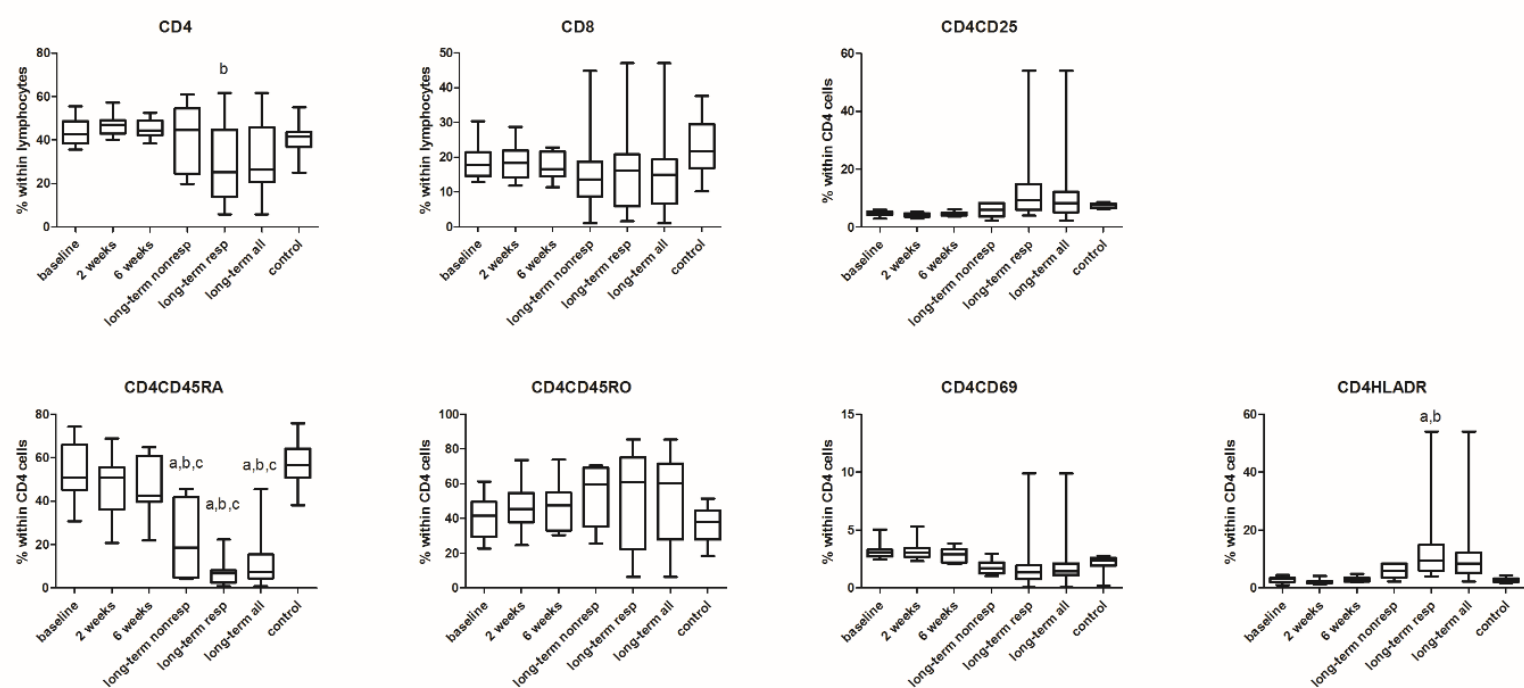

CD8CD45RA

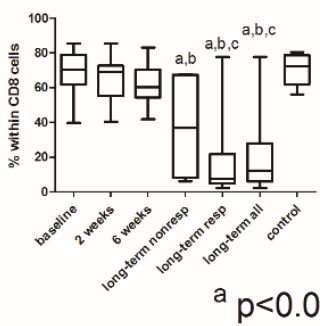

CD8CD45RO
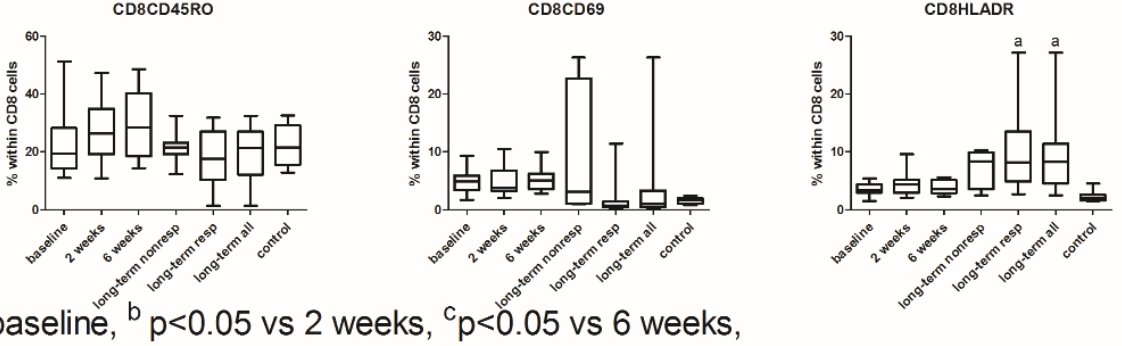

Figure 9. Changes in the proportions of T-cell subsets in anyklosing spondylitis patient groups: comparison between short-term and long-term treatment

Data are presented from the initiation of anti-TNF therapy; baseline: at the start of anti-TNF therapy $n=13 ; 2$ weeks: after 2 weeks of anti-TNF therapy $n=13 ; 6$ weeks: after 6 weeks of antiTNF therapy $n=12$ (54); long-term anti-TNF-responders $(n=15) ;$ long-term anti-TNF-nonresponders ( $n=7) ;$ long-term all: the two long-term subgroups together $(n=22) ;$ and healthy controls $(n=10) .{ }^{a} p<0.05$ vs baseline, ${ }^{b} p<0.05$ vs after 2 weeks, ${ }^{c} p<0.05$ vs after 6 weeks, ${ }^{d} p<0.05$ vs control.For CD4CD25 and CD4CD69, ANOVA revealed a significant $(p=0.018)$ 
difference among the groups, but the Bonferroni post hoc test did not identify any significant difference between the particular subgroups individually.
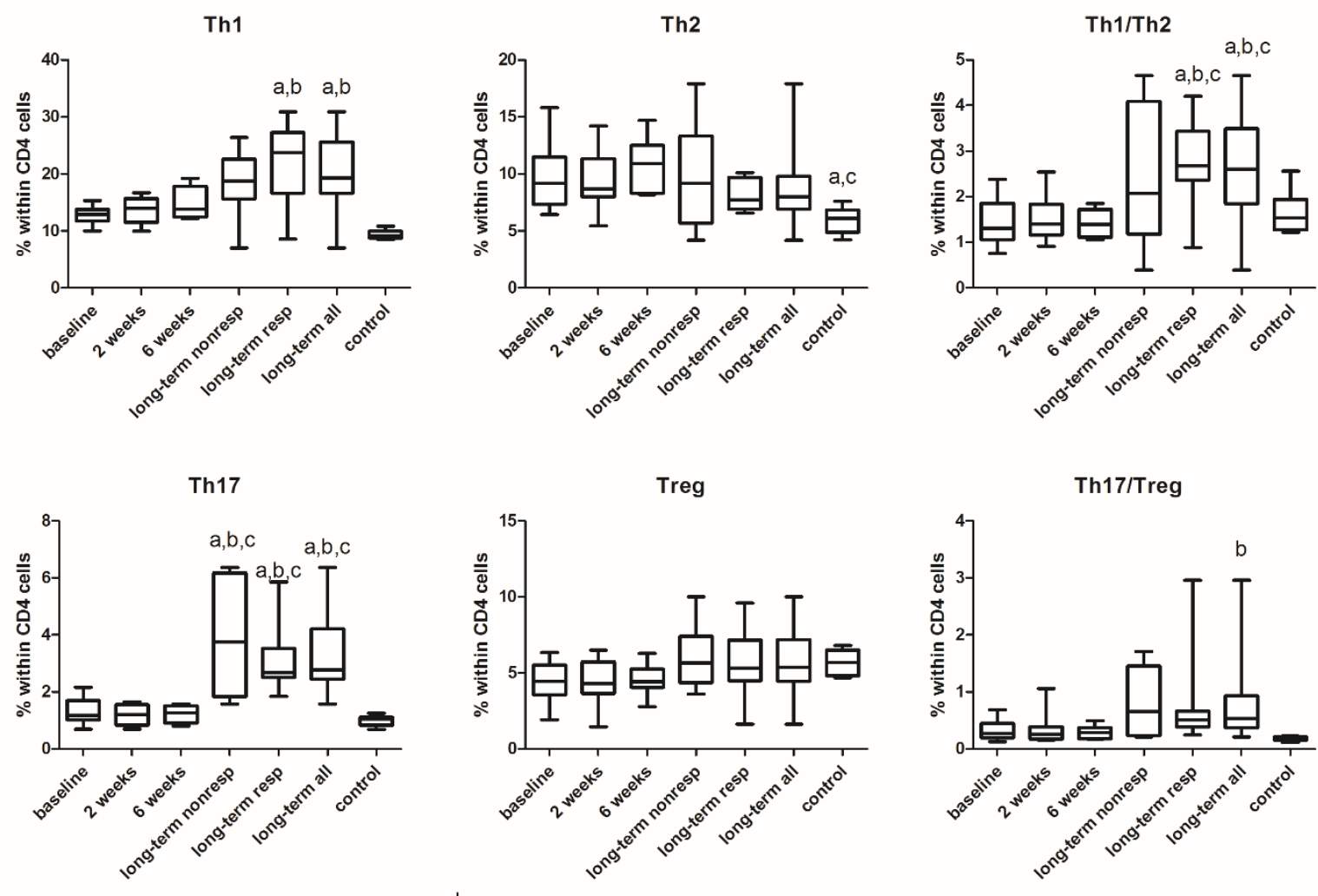

${ }^{a} p<0.05$ vs baseline, ${ }^{b} p<0.05$ vs 2 weeks, ${ }^{c} p<0.05$ vs 6 weeks

Figure 10. Changes in the proportions of the major effector T-helper cell subsets in ankylosing spondylitis patient groups: comparison between short-term and long-term treatment.

Data are presented from the initiation of anti-TNF therapy; baseline: at the start of anti-TNF therapy $n=13 ; 2$ weeks: after 2 weeks of anti-TNF therapy $n=13 ; 6$ weeks: after 6 weeks of antiTNFtherapy $n=12$ (54); long-term anti-TNF-responders $(n=15)$; long-term anti-TNF-nonresponders ( $n=7)$; long-term all: the two long-term subgroups together $(n=22) ;$ and healthy controls $(n=10) .{ }^{a} p<0.05$ vs baseline, ${ }^{b} p<0.05$ vs after 2 weeks, ${ }^{c} p<0.05$ vs after 6 weeks, ${ }^{d} p<0.05$ vs control 


\subsection{Inflammatory bowel diseases}

\subsubsection{Clinical follow-up}

The mean follow-up time of the patients after the blood sampling and the initiation of anti-TNF therapy was 35 months for CD and 24 months for UC patients. Follow-up data are summarized in Table 9. Long-term therapeutic response was observed in more than half of the patients (14 of 16 in CD and 9 of 16 in UC patients). In UC patients, primary non-response occurred more frequently than secondary inefficacy of anti-TNF therapy. The disease relapsed within 12 months in 9 of the 11patients in whom anti-TNF was stopped after one year of successful therapy, and in only 2 of them was a biologic-free remission observed, during a follow-up period of 12 and 36 months, respectively.

\begin{tabular}{|l|c|c|}
\hline & CD (n=16) & UC (n=16) \\
\hline Duration of follow-up (months) & $35(16-47)$ & $24(2-46)$ \\
\hline Short-term response achieved & 15 & 9 \\
\hline Long-term response achieved & 14 & $19(0-46)$ \\
\hline Duration of response (months) & $27(0-47)$ & 12 \\
\hline
\end{tabular}

Table 9. Disease outcome after the initiation of anti-TNF therapy in IBD patients.

For 4 UC patients, follow-up was shorter than 12 months, long-term response was therefore evaluable in 20 patients. For the definition of short-term and long-term response, see Patients section

\subsubsection{Lymphocyte subset distribution}

We have revealed a number of significant differences between healthy controls and IBD patients with respect of the prevalences of several T-cell subsets. ANOVA analyses have indicated that patients in every CD or UC subgroup had higher frequencies of Th2 and Th17 cells (Figure 11) than healthy controls. 
Th1

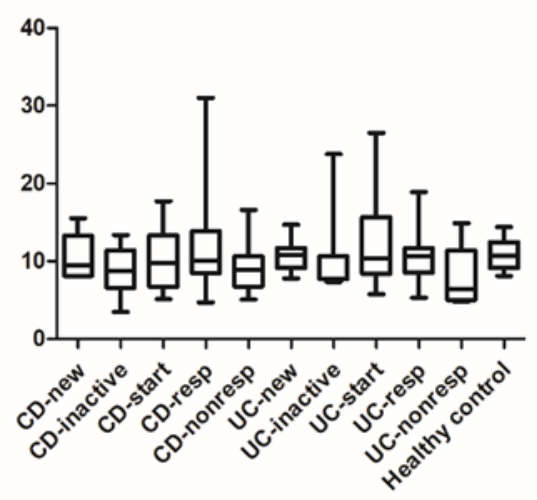

Th17

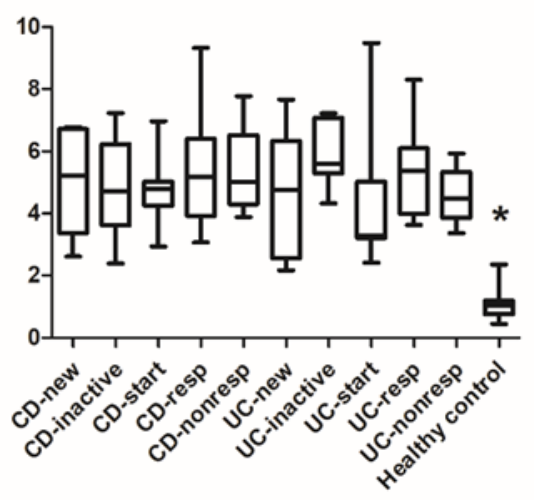

Th2

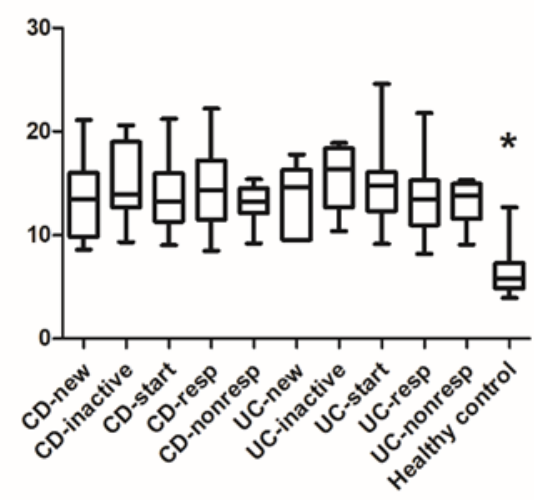

Treg

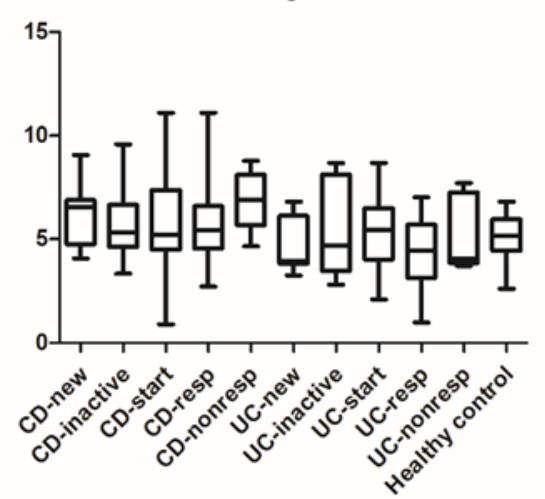

Figure 11. Comparison of the frequencies of the major The effector cell subsets among the various patient groups and controls.

CDnew: new-onset Crohn's disease (CD) patients, CDinact: $C D$ patients with inactive disease on immunosuppressive therapy, CDstart: patients with active CD in whom anti-TNF therapy is initiated, CDresp: anti-TNF-responder CD patients, CDnonresp: anti-TNF-nonresponder CD patients. Abbreviations are analogous for ulcerative colitis (UC) patients.Data are presented as median (horizontal line within boxes), 25 and 75 percentile (horizontal borders of the boxes), and minimum and maximum (whiskers). Numbers on the vertical axis indicate \% within CD4 cells. *: p<0.05 for the comparison between healthy controls and all other patient subgroups with ANOVA and Bonferroni's correction 

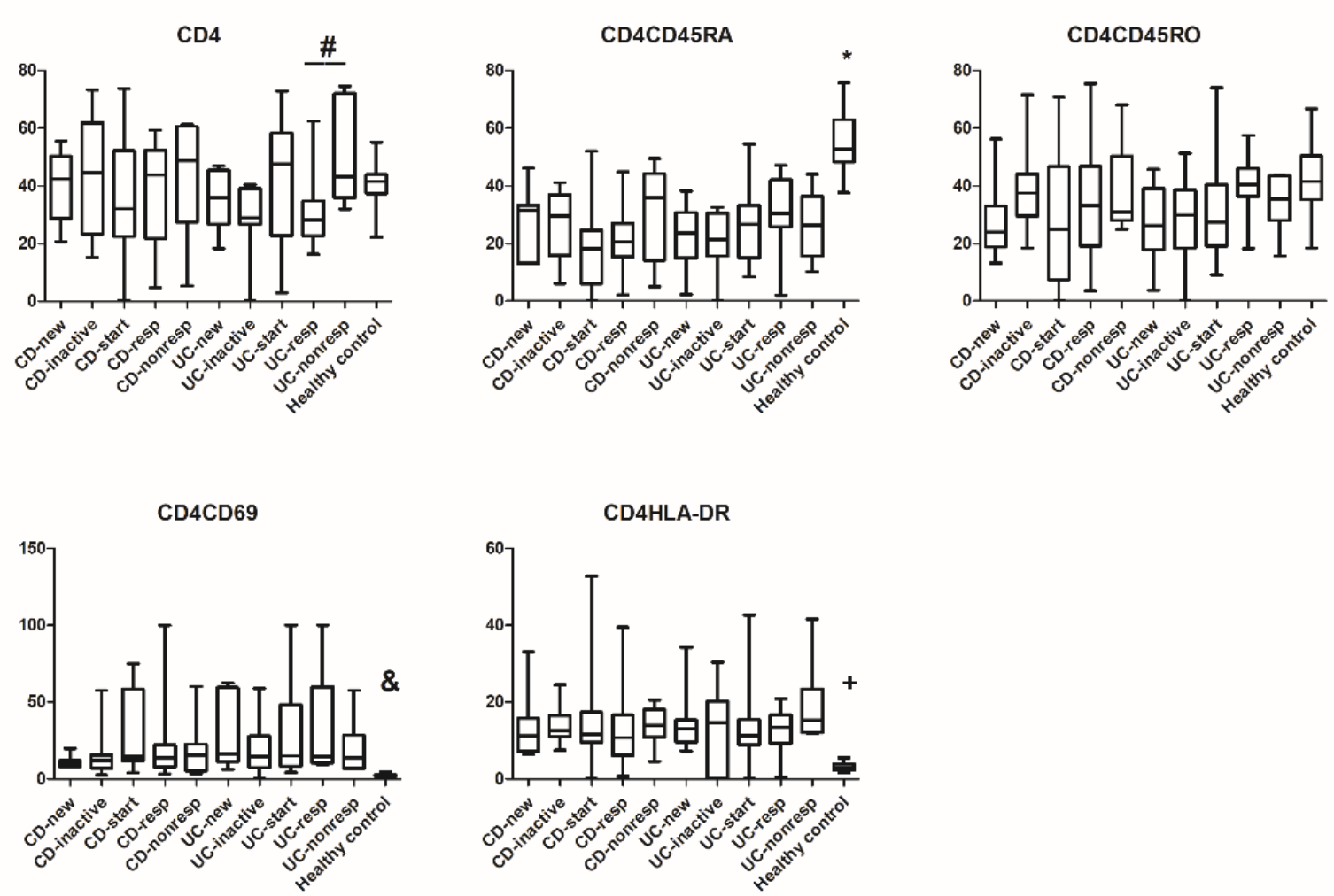

Figure 12. Comparison of the frequencies of CD4 cell subsets among the various patient groups and controls.

For the explanation of the abbreviations of patient subgroups bars and whiskers, please see Legend to Figure 11. Numbers on the vertical axis indicate \% within lymphocytes (for CD4) or $\%$ within CD4 cells (all other).

*: $p<0.05$ for the comparison between healthy controls and all other patient subgroups with ANOVA and Bonferroni's correction

$\&: p<0.05$ for the comparison between healthy controls and all other patient subgroups with the exception of CDnew, with ANOVA and Bonferroni's correction

+: $p<0.05$ for the comparison between healthy controls and CDnew, CDinact, CDstart, CDresp, UCstart and UCnonresp patients with ANOVA and Bonferroni's correction \#: $p<0.05$ for the comparison between UCresp and UCnonresp with Student's t-test 
Although the proportion of CD4 cells was comparable across all groups, patients in all IBD subgroups had less naive (CD45RA) T-cells than healthy controls, whereas the proportion of activated (CD69 and HLA-DR) T-cells was higher in most IBD subgroups, especially in CD patients, than in healthy controls (Figure 12). In the CD8 compartment, similar conclusions can be drawn, with the addition that the prevalence of memory T-cells (CD45RO) proved to be statistically significantly higher in $2 \mathrm{CD}$ and $1 \mathrm{UC}$ subgroup too (Figure 13).
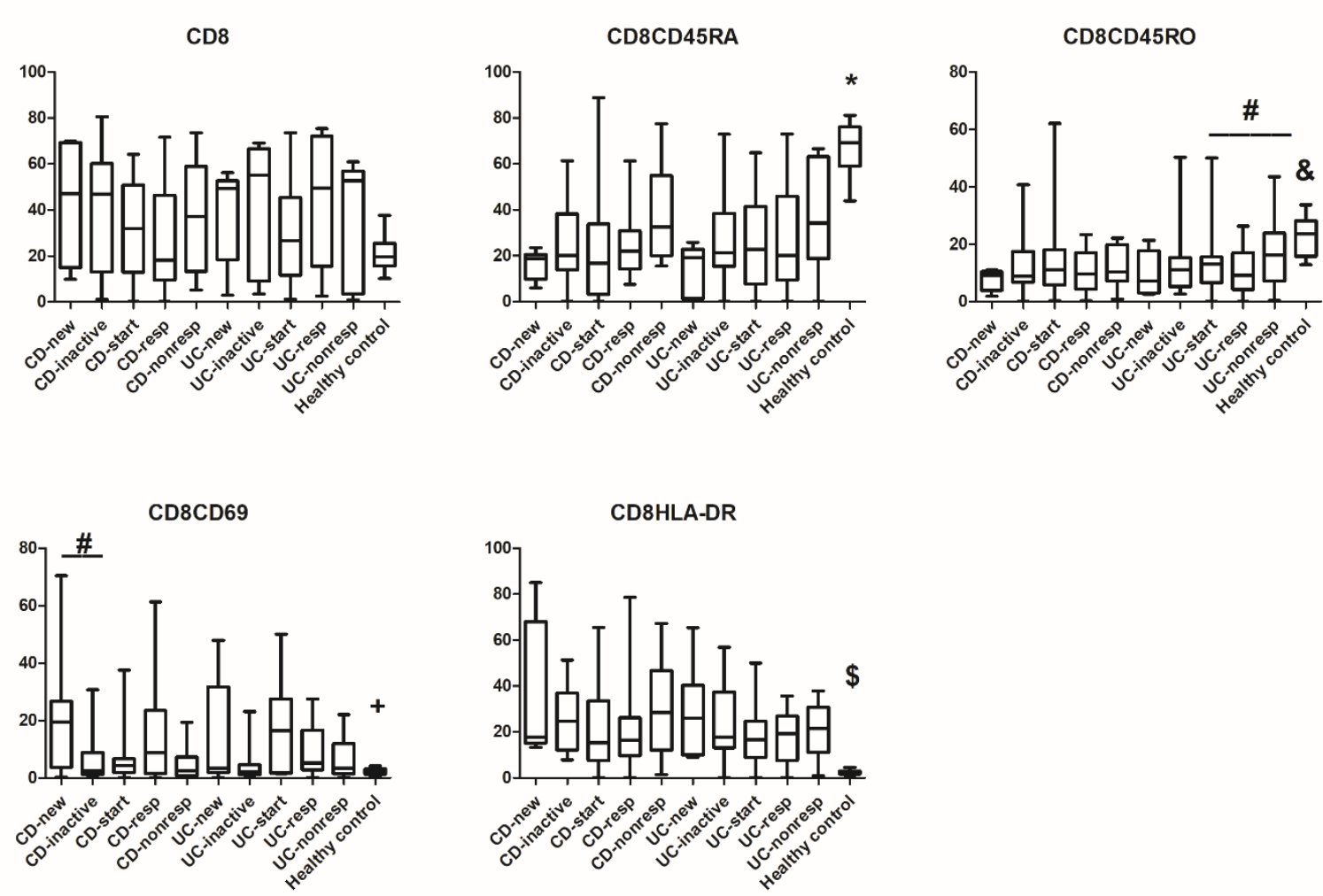

Figure 13. Comparison of the frequencies of CD8 cell subsets among the various patient groups and controls

For the explanation of the abbreviations of patient subgroups, and bars and whiskers, please see Legend to Figure 11.Numbers on the vertical axis indicate \% within lymphocytes (CD8 cells) or \% within CD8 cells (all other).

*: $p<0.05$ for the comparison between healthy controls and all other patient subgroups with ANOVA and Bonferroni's correction 
$\&: p<0.05$ for the comparison between healthy controls and CDnew, CDresp and UCresp patients with ANOVA and Bonferroni's correction

$+:$ p<0.05 for the comparison between healthy controls and CDnew, CDresp and UCstart patients with ANOVA and Bonferroni's correction

\$: $p<0.05$ for the comparison between healthy controls and CDnew, CDstart, CDresp, CDnonresp and UCnew patients with ANOVA and Bonferroni's correction

\#: $p<0.05$ for the comparison between UCstart and UCnonresp (CD8CD45RO), and between CDnew and CDinact (CD8CD69) with Student's t-test

However, in contrast with our previous studies on RA and AS patients, relatively few differences could be demonstrated between newly diagnosed cases and patients in remission, and among patients before and after the initiation of anti-TNF therapy. Significant differences among the various patient subgroups in the cross- sectional part are as follows: CD4 proportion was lower in anti-TNF responder UC patients than in non-responders; CD8CD69 activated Tcells were observed more frequently in newly diagnosed CD patients than in those whose disease has become inactive with conventional immunosuppressive therapy; and CD8 memory cell prevalence was higher in anti-TNF non-responder UC patients than in UC patients at the time of anti-TNF-initiation.

We also attempted to compare the changes that occur in the cell subset distribution during antiTNF therapy with the analysis of the data on patients in whom repeated measurements were performed, i.e. the T-cell profile at the initiation of anti-TNF could be compared with that after at least 3 months of therapy. Unfortunately, the numbers of eligible patients was fairly low as only 3 responder and non-responder patients could be compared in both IBD-s. These analyses could, therefore, not reveal any statistically evaluable difference, although the numbers indicating the changes in the cell prevalence values are strikingly different for many cell subtypes, in particular for Th2 in UC, and CD8CD69 and the naïve/memory composition in both diseases, therefore we have summarized these figures in Table 10. In contrast with our previous findings in RA and AS, Treg prevalence was not affected by anti-TNF therapy in either IBD. 


\begin{tabular}{|c|c|c|c|}
\hline Cell subtypes & $\begin{array}{l}\text { Responder vs Non- } \\
\text { responder }\end{array}$ & Mean (UC patients) & Mean (CD patients) \\
\hline \multirow{2}{*}{ Th1 } & Non-responder & $-4,513$ & $-6,043$ \\
\hline & Responder & $-9,683$ & $-3,540$ \\
\hline \multirow{2}{*}{ Th2 } & Non-responder & $-7,167$ & 2,607 \\
\hline & Responder & $-0,8700$ & 0,2667 \\
\hline \multirow{2}{*}{ Th17 } & Non-responder & $-0,6200$ & 1,050 \\
\hline & Responder & 0,2967 & 0,8467 \\
\hline \multirow{2}{*}{ Treg } & Non-responder & 1,123 & 0,7033 \\
\hline & Responder & $-0,6267$ & 2,213 \\
\hline \multirow{2}{*}{ CD4 } & Non-responder & 10,14 & 4,290 \\
\hline & Responder & 10,43 & 27,00 \\
\hline \multirow{2}{*}{ CD4CD45RA } & Non-responder & $-3,433$ & 0,1433 \\
\hline & Responder & 4,467 & 27,64 \\
\hline \multirow{2}{*}{ CD4CD45RO } & Non-responder & 23,47 & 45,67 \\
\hline & Responder & 7,733 & 11,87 \\
\hline \multirow{2}{*}{ CD4CD69 } & Non-responder & $-16,97$ & $-30,78$ \\
\hline & Responder & $-18,05$ & $-34,99$ \\
\hline \multirow{2}{*}{ CD4HLA-DR } & Non-responder & 5,987 & $-16,90$ \\
\hline & Responder & $-9,533$ & 6,590 \\
\hline \multirow{2}{*}{ CD8 } & Non-responder & 2,100 & 29,23 \\
\hline & Responder & 20,18 & 24,10 \\
\hline \multirow{2}{*}{ CD8CD45RA } & Non-responder & 32,88 & 17,09 \\
\hline & Responder & 13,89 & 14,24 \\
\hline \multirow{2}{*}{ CD8CD45RO } & Non-responder & 3,003 & $-13,36$ \\
\hline & Responder & 15,43 & 0,1667 \\
\hline \multirow{2}{*}{ CD8CD69 } & Non-responder & $-1,847$ & 7,197 \\
\hline & Responder & $-24,98$ & $-9,097$ \\
\hline \multirow{2}{*}{ CD8HLA-DR } & Non-responder & 10,42 & 17,80 \\
\hline & Responder & 15,20 & 30,22 \\
\hline
\end{tabular}

Table 10. Changes in the cell subtype prevalence values during anti-TNF therapy in UC and $C D$ patients, in whom repeated measurements were available.

Numbers indicate differences between percentage values during follow-up: \% after at least 3 months of follow-up - \% at start of anti-TNF. Six CD and 6 UC patients were analyzed (3each in both responder and non-responder groups). 
Finally, we analyzed if any of the cell prevalence values had a predictive value for the favourable clinical response to anti-TNF therapy. To answer that, we have performed ROC analyses in the CDstart and UCstart groups to search for frequency values that could discriminate between patients with and without long-term remission, and we carried out correlation analysis between the cell percentages and the duration of remission. In CD patients, CD4CD45RO cell prevalence of $<49.05 \%$ has predicted the long-term remission with a sensitivity of $100 \%$ (95\% confidence interval:15.81\% to $100.0 \%$ ) and a specificity of $92.3 \%$ (95\% confidence interval: 63.97 to $99.81 \%$ ), and a likelihood ratio of 13.01. CD4HLADR cell frequencies showed a near-significant $(\mathrm{p}=0.058)$ correlation with the duration of remission (Pearson's $\mathrm{r}=0.50)$. In UC patients, there was a trend to significance $(\mathrm{p}=0.08)$ for a CD4 prevalence value of < 29.95 (sensitivity: $66.67 \% 95 \%$ CI: $9.43 \%$ to $99.16 \%$, specificity $87.50 \%$

(95\% CI 47.35\% to 99.68\%), likelihood ratio: 5.33), and Th2 and Th17 cell prevalence values showed a significant positive correlation with the duration of response $(p=0.03$, Pearson's $r$ : 0.59 , and $\mathrm{p}=0.03$, Pearson's $\mathrm{r}$ : 0.61 , respectively), and a tendency with regard to a positive correlation with CD8HLADR ( $\mathrm{p}=0.06$, Pearson's r: 0.59).

\section{Discussion}

Our primary intention was to find laboratory parameters that would help clinicians to make scientifically established treatment decisions. In other words: to see if any of the $14 \mathrm{~T}$-cell subtypes are useful in the decision if anti-TNF or - in RA - IL6R blocker therapy is expectably beneficial in the given patient, or conversely, the likelihood of refractoriness to these therapies is high. Therefore we highlight biomarkers that have predictive potential: in RA we found that CD4CD69 ratio is sensitive and specific to remission with anti-TNF agents, furthermore, CD8CD69 in both IBDs, and CD4CD45RO in CD are also remarkable. RA patients with high CD4CD69 or CD8CD69 probably benefit from switching to IL6R-blocking therapy after antiTNF-failure instead of choosing a second anti-TNF. In CD patients, CD8CD69 can be regarded as an activity marker, furthermore, it is associated with treatment response to anti-TNF in UC. This suggests that T-cell typing by flow cytometry can be a potential diagnostic tool to select which class of targeted therapy is are a better choice.

Why it is important to know the T-cell composition during anti-TNF therapy? First, because the mechanism of action of these drugs is not fully understood. TNF- $\alpha$ impairs the activation of T-lymphocytes in response to antigen (93), and it induces the apoptosis of activated T-cells 
by binding to TNF-receptor-I or -II (94). Anti-TNF agents reverse the activation-blocking effects of TNF- $\alpha$ (93), and thus could help activated cells to proliferate, but they can also induce apoptosis in T-cells, with differences among the particular drugs: infliximab, adalimumab and golimumab increase spontaneous apoptosis in these cells, while certolizumab pegol and etanercept do not (95). These effects may alter the composition of the T-cell subsets, but most of these results come from in vitro studies, and we do not know if they really exist in real life. Secondly, because most of the patients receive anti-TNF drugs for many years, and the longterm consequences of this treatment is not completely clear - for example, is there an increased risk of tumor development if certain T-cell subsets that are important in antitumor immune response decrease in number of function?

In anti-TNF-treated RA and AS, an important observation we made was that the main characteristics of T-cells reflect an activated state of the immune system, with one important exception: the normalization of Treg frequencies. We explain the first finding by the fact that both anti-TNF and anti-IL-6R therapies exert their action by the inhibition of the terminal phase of the effector arm of the autoimmune process (i.e. cytokine action), and the differentiation and the activation of naive T-cells by the permanent antigenic stimuli might be left unchanged. The normalization in Treg proportion starts soon after the initiation of anti-TNF-therapy, but the changes become statistically significant only after long-term treatment. Restoration of tolerance, as shown by the normalization of Treg numbers, seems to be a consistent phenomenon during the prolonged therapy of RA and also in AS. A further factor that should be considered is that despite Th17 prevalence remained increased, the ratio of Th17/Treg tended to approach the ratio observed in healthy controls in inflammatory rheumatic diseases. Analogously to our findings, Teniente-Serra et al have found that multiple sclerosis patients treated with natalizumab (monoclonal antibody to the integrin CD49d) had an increased percentage of early effector and central memory T cells, as well as of early thymic emigrant Tcells, as compared with untreated patients, indicating that T-cell activation may proceed despite the inflammatory process is blocked by the inhibition of the effector steps (96). The expansion of Th17 and Th1 cells has also been described by other authors $(97,98)$.

A potential explanation was presented by Notley et al, who have shown that anti-TNF treatment of mice in the collagen-induced arthritis model lead to the up-regulation of the p40 subunit of IL12/23 receptor, and a resulting increase in both Th17 and Th1 cell frequencies (99). They explained the reduction in collagen-induced arthritis activity in anti-TNF-treated mice with their observation that the amount of Th1 and Th17 cells in the synovium markedly decreased 
while they expanded in the blood and lymph nodes. In RA patients, Th1 and Th17 cells and IL17 production was found to increase during anti-TNF therapy, and it was independent of the clinical response (97). However, CCR6 expression was significantly down-regulated in Th17 cells of RA patients in remission under anti-TNF therapy as compared with those with active disease (97). It was also found that TNF- $\alpha$ inhibits the expansion of effector CD4 and CD8 Tcells during viral infection by inducing apoptosis (100), so the blockade of TNF- $\alpha$ might release the activated T-cells from this negative regulation.

These findings suggest that, in spite of the increased amount of the circulating proinflammatory T-cells during anti-TNF therapy, the inactivity of the disease is maintained by alterations in various effector functions of these cells. It can also be concluded that the potential of the immune system to protect from tumor development and from infections persists during even several years of biological therapies, as the response to antigenic stimuli and the activation of $\mathrm{T}$-cells seems to be preserved by the analysis of naive/memory and resting/activated $\mathrm{T}$ lymphocyte subtypes.

In contrast to RA and AS, we have detected only subtle changes in IBD patients during antiTNF therapy. Peripheral blood Treg frequency remained stable, and only total CD4 and CD8 memory cell percentages showed a difference in anti-TNF-treated UC patients. Our hypothesis for this discrepancy is that in IBDs the most relevant immunological events happen in the gut mucosa-associated immune system, and are reflected less in the circulating lymphocyte pool than in RA and AS. We propose therefore that studies on the pharmacodynamic immunological effects of anti-TNF, and possibly other novel targeted therapies are more appropriate from mucosal biopsies than from peripheral blood, or parallel samplings from endoscopic biopsies and peripheral blood should be performed. We note that peripheral blood T-cell composition did prove to be useful for the description of the adaptive immune system when CD and UC patients were compared with healthy individuals. It may be possible that an even longer followup would be needed until the putative mucosal immune alterations would proceed to the systemic immune system.

Our investigations involved several $\mathrm{T}$ cell subsets in all the diseases that have not been studied before. All untreated patient groups showed shifted immune cell balance from healthy controls, such as Th2 which was elevated in both RA and in IBDs compared to healthy controls. Th17 percentage was elevated in IBDs, but not in the inflammatory rheumatic diseases. Regulatory $\mathrm{T}$ cell frequencies were lower in RA and AS patients. Various activated T cell subtype 
proportions were different in all examined diseases. CD4CD69, CD4HLA-DR, CD8-HLA-DR in RA, CD4HLA-DR, CD4CD25, CD8CD69 and CD8HLA-DR in AS, and CD4CD69, CD4HLA-DR, CD8CD69 and CD8HLA-DR in IBD all differed from healthy controls. Naïve $\mathrm{T}$-cell frequency was lower in all diseases than in controls.

The proportions of various lymphocyte subsets during IL-6R-blocker therapy was previously investigated in detail in only one study (43). Our results add further knowledge to their results by including several T-cell subtypes not analyzed before, and the inclusion of a healthy control group. Common findings in their examinations and ours are the importance of the normalization of Treg counts, and the decrease in the frequencies of CD8 cells, naive T-cells, and an increase in that of CD69 activated T-cells. Although they did not find a significant change in Th1, Th2 or Th17 prevalences, their results also underline that activated cell subtype frequencies do not decrease during tocilizumab treatment. The importance of CD4CD69 as a predictive biomarker appears in IL6R-treated patients too: in those who had previously produced three times an incomplete response to anti-TNF therapy, the prevalences of CD4CD69 and CD8CD69 markers are significantly higher than in those who failed only one anti-TNF inhibitor before. It follows that, since all the above-mentioned anti-TNF non-responders with three switches (and with high CD4CD69 and CD8CD69 expression) became long-term anti-IL-6R responders, we propose that patients not responding to one anti-TNF, and having high CD4CD69 expression should be switched to anti-IL-6R therapy. 


\section{Summary}

Our key findings are:

1. Long-term biological therapy normalizes the decreased Treg prevalence in RA and AS.

2. The T-cell phenotype of RA and AS patients on long-term anti-TNF therapy is featured by decreased naive CD4 and CD8 cell percentage, and many of the activated or effector (i.e. Th1, Th2 or Th17) subtypes were more prevalent, while some of the activated subtypes had lower frequency.

3. We have provided a detailed description of the T-cell composition in patients treated with the Il6R-blocker tocilizumab.

4. CD4CD69 T-cell percentage $<2.43$ at the start of anti-TNF predicts a future response to this type of therapy in RA. Patients with more anti-TNF failures have higher CD4CD69 and CD8CD69 expression than those who only had one non-response to anti-TNF.

5. The immune phenotype after short-term and long-term anti-TNF therapy is markedly different in RA and AS; changes become obvious only after at least 3 months of anti-TNF treatment, but after 6 months of therapy, there are no further notable changes.

6. IBD (both UC and CD) patients have higher prevalence of Th2 and Th17 effector T-cells and lower frequency of CD45RA naive T-cells than healthy controls, whereas the proportion of activated (CD69 and HLA-DR) T-cells is higher in most IBD subgroups, especially in CD patients, than in healthy subjects.

7. In CD patients, CD8CD69 percentage is increased in active disease, and it decreases with treatment response to anti-TNF in UC.

8. In CD patients, CD4CD45RO cell prevalence of $<49.05 \%$ is a predictor of long-term remission. In UC patients, Th2 and Th17 cell prevalence values showed a significant positive correlation with the duration of treatment response. 


\section{Acknowledgements:}

I am grateful to my tutor, Attila Balog $\mathrm{MD}, \mathrm{PhD}$ for his continuous and altruistic professional help, for his encouragement, guidance and constructive critiques, and to László Kovács MD, $\mathrm{PhD}$ for the organization of the unimpeded work activities. Furthermore, I thank Gergely Toldi $\mathrm{MD}, \mathrm{PhD}$ and the members of his team, in particular Sava Florentina $\mathrm{PhD}$, Zsófia Vásárhelyi and László Berta, and also Szilvia Pördi for their assistance in the experiments and coauthorship. I also thank Professor Tamás Molnár MD, PhD, DSc and his colleagues for the facilitation of the organization of the examinations of the IBD patients. I am indebted to my family, most importantly JD Ádám Tepper, Katalin Dulic, Gavro Dulic and JD. Ágnes Tepper for their perpetual support and encouragement.

\section{References:}

1. Smolen JS, Aletaha D, Barton A, Burmester GR, Emery P, Firestein GS, et al Rheumatoid arthritis. Nat Rev Dis Primers. 2018 8;4:18001.

2. Tanaka T, Hishitani Y, Ogata A. Monoclonal antibodies in rheumatoid arthritis: comparative effectiveness of tocilizumab with tumor necrosis factor inhibitors. Biologics. 2014;8:141-53.

3. Hyrich KL, Watson KD, Silman AJ, Symmons DP; British Society for Rheumatology Biologics Register. Predictors of response to anti-TNF-alpha therapy among patients with rheumatoid arthritis: results from the British Society for Rheumatology Biologics Register. Rheumatology (Oxford). 2006;45(12):1558-65

4. Furst DE, Pangan AL, Harrold LR, Chang H, Reed G, Kremer JM et al. Greater likelihood of remission in rheumatoid arthritis patients treated earlier in the disease course: results from the Consortium of Rheumatology Researchers of North America registry. Arthritis Care Res (Hoboken). 2011;63(6):856-64.

5. Kristensen LE, Kapetanovic MC, Gülfe A, Söderlin M, Saxne T, Geborek P. Predictors of response to anti-TNF therapy according to ACR and EULAR criteria in patients with established RA: results from the South Swedish Arthritis Treatment Group Register. Rheumatology (Oxford). 2008;47(4):495-9.

6. Abhishek A, Butt S, Gadsby K, Zhang W, Deighton CM. Anti-TNF-alpha agents are less effective for the treatment of rheumatoid arthritis in current smokers. J Clin Rheumatol. 2010;16(1):15-8. 
7. Chen DY, Chen YM, Chen HH, Hsieh CW, Lin CC, Lan JL. Increasing levels of circulating Th17 cells and interleukin-17 in rheumatoid arthritis patients with an inadequate response to anti-TNF- $\alpha$ therapy. Arthritis Res Ther. 2011;13(4):R126.

8. van Baarsen LG, Wijbrandts CA, Rustenburg F, Cantaert T, van der Pouw Kraan TC, et al. Regulation of IFN response gene activity during infliximab treatment in rheumatoid arthritis is associated with clinical response to treatment. Arthritis Res Ther. 2010;12(1):R11.

9. Centola M, Cavet G, Shen Y, Ramanujan S, Knowlton N, Swan KA, et al.Development of a multi-biomarker disease activity test for rheumatoid arthritis. PLoS One. 2013;8(4):e60635.

10. Hambardzumyan K, Saevarsdottir S, Forslind K, Petersson IF, Wallman JK, Ernestam S, et al. A Multi-Biomarker Disease Activity Score and the Choice of Second-Line Therapy in Early Rheumatoid Arthritis After Methotrexate Failure. Arthritis Rheumatol. 2017;69(5):953-963.

11. Wang Y, Wang H, Jiang J, Zhao D, Liu Y. Comparative Efficacy and Acceptability of Anti-TNF-Alpha Therapy in Ankylosing Spondylitis: A Mixed-Treatments Comparison. Cell Physiol Biochem. 2016;39(5):1679-1694.

12. Baraliakos X, Koenig AS, Jones H, Szumski A, Collier D, Bananis E. Predictors of Clinical Remission under Anti-tumor Necrosis Factor Treatment in Patients with Ankylosing Spondylitis: Pooled Analysis from Large Randomized Clinical Trials. J Rheumatol. 2015;42(8):1418-26

13. Arends S, Brouwer E, van der Veer E, Groen H, Leijsma MK, Houtman PM, et al. Baseline predictors of response and discontinuation of tumor necrosis factor-alpha blocking therapy in ankylosing spondylitis: a prospective longitudinal observational cohort study. Arthritis Res Ther. 2011;13(3):R94.

14. Szántó S, Aleksza M, Mihály E, Lakos G, Szabó Z, Végvári A, et al. Intracytoplasmic cytokine expression and $\mathrm{T}$ cell subset distribution in the peripheral blood of patients with ankylosing spondylitis. Rheumatol. 2008;35(12):2372-5.

15. Sherlock JP, Joyce-Shaikh B, Turner SP, Chao CC, Sathe M, Grein J, et al. IL-23 induces spondyloarthropathy by acting on ROR- $\gamma \mathrm{t}+\mathrm{CD} 3+\mathrm{CD} 4-\mathrm{CD} 8$ - entheseal resident T cells. Nat Med. 2012;18(7):1069-76.

16. Ford AC, Sandborn WJ, Khan KJ, et al. Efficacy of biological therapies in inflammatory bowel disease: systematic review and meta-analysis. Am J Gastroenterol 2011; 106: 644659 
17. Billioud V, Sandborn WJ, Peyrin-Biroulet L. Loss of response and need for adalimumab dose intensification in Crohn's disease: a systematic review. Am J Gastroenterol 2011; 106: 674-684

18. Lopetuso LR, Gerardi V, Papa V, Scaldaferri F, Rapaccini GL, Gasbarrini A, et al. Can We Predict the Efficacy of Anti-TNF- $\alpha$ Agents? Int J Mol Sci. 2017;18(9). pii: E1973.

19. Maul J, Loddenkemper C, Mundt P, Berg E, Giese T, Stallmach A, et al. Peripheral and intestinal regulatory CD4+ CD25(high) $\mathrm{T}$ cells in inflammatory bowel disease Gastroenterology. 2005;128(7):1868-78.

20. Khor B1, Gardet A, Xavier RJ. Genetics and pathogenesis of inflammatory bowel disease. Nature. 2011;474(7351):307-17.

21. Aeberli D, Seitz M, Jüni P, Villiger PM. Increase of peripheral CXCR3 positive T lymphocytes upon treatment of RA patients with TNF-alpha inhibitors. Rheumatology (Oxford) 2005; 44(2):172-175.

22. Yang PT, Kasai H, Zhao LJ, Xiao WG, Tanabe F, Ito M. Increased CCR4 expression on circulating CD4(+) T cells in ankylosing spondylitis, rheumatoid arthritis, and systemic lupus erythematosus. Clin Exp Immunol 2004; 138(2):342-347.

23. Chavele KM, Ehrenstein MR. Regulatory T cells in systemic lupus erythematosus and rheumatoid arthritis. FEBS Lett 2011; 585(23):3603-3610.

24. Gaffen SL The role of interleukin-17 in the pathogenesis of rheumatoid arthritis. Curr Rheumatol Rep 2009; 11:365-370.

25. Byng-Maddick R, Ehrenstein MR. The impact of biological therapy on regulatory T cells in rheumatoid arthritis. Rheumatology (Oxford). 2015; 54(5):768-775.

26. Szalay B , Vásárhelyi B , Cseh A, Tulassay T, Deák M, Kovács L et al. The impact of conventional DMARD and biological therapies on CD4+ cell subsets in rheumatoid arthritis: a follow-up study. Clin Rheumatol 2014; 33(2): 175-185.

27. Skapenko A, Leipe J, Lipsky PE, Schulze-Koops H. The role of the T cell in autoimmune inflammation. Arthritis Res Ther. 2005;7 Suppl 2:S4-14

28. Kohem CL, Brezinschek RI, Wisbey H, Tortorella C, Lipsky PE, Oppenheimer-Marks N. Enrichment of differentiated CD45RBdim,CD27- memory T cells in the peripheral blood, synovial fluid, and synovial tissue of patients with rheumatoid arthritis. Arthritis Rheum. 1996;39(5):844-54.

29. Neidhart M, Fehr K, Pataki F, Michel BA. The levels of memory (CD45RA-, RO+) CD4+ and CD8+ peripheral blood T-lymphocytes correlate with $\operatorname{IgM}$ rheumatoid factors in rheumatoid arthritis. Rheumatol Int. 1996;15(5):201-9. 
30. Smoleńska Ż, Pawłowska J, Daca A, Soroczyńska-Cybula M, Witkowski J, Bryl EM. Disease activity in patients with long-lasting rheumatoid arthritis is associated with changes in peripheral blood lymphocyte subpopulations. Pol Arch Med Wewn. 2012;122(12):591-8.

31. Pawłowska J, Smoleńska Z, Daca A, Witkowski JM, Bryl E. Older age of rheumatoid arthritis onset is associated with higher activation status of peripheral blood CD4(+) T cells and disease activity. Clin Exp Immunol. 2011;163(2):157-64.

32. Lurati A, Laria A, Gatti A, Brando B, Scarpellini M. Different T cells' distribution and activation degree of Th17 CD4+ cells in peripheral blood in patients with osteoarthritis, rheumatoid arthritis, and healthy donors: preliminary results of the MAGENTA CLICAO study. Open Access Rheumatol. 2015; 7:63-68.

33. Ichikawa Y, Shimizu H, Yoshida M, Arimori S. Activation antigens expressed on T-cells of the peripheral blood in Sjögren's syndrome and rheumatoid arthritis. Clin Exp Rheumatol. 1990;8(3):243-9.

34. Yue C, 'You X, Zhao L, Wang H, Tang F, Zhang F et al. The effects of adalimumab and methotrexate treatment on peripheral Th17 cells and IL-17/IL-6 secretion in rheumatoid arthritis patients. Rheumatol Int 2010; 30:1553-1557.

35. Aravena O, Pescea B, Soto L, Orrego N, Sabugo F, Wurmann P et al. Anti-TNF therapy in patients with rheumatoid arthritis decreases Th1 and Th17 cell populations and expands IFN-r-producing NK cell and regulatory T cell subsets. Immunobiology 2011; 216:12561263.

36. Hull DN, Williams RO, Pathan E, AlzabinS, Abraham S, Taylor PC. Anti-tumour necrosis factor treatment increases circulating T helper type 17 cells similarly in different types of inflammatory arthritis. Clin Exp Immunol 2015; 181(3):401-406.

37. Huang Z, Yang B, Shi Y, Cai B, Li Y, Feng W et al. Anti-TNF- $\alpha$ therapy improves Treg and suppresses Teff in patients with rheumatoid arthritis. Cell Immunol 2012; 279(1):2529

38. Lina C, Conghua W, Nan L, Ping Z. Combined Treatment of Etanercept and MTX Reverses Th1/Th2, Th17/Treg Imbalance in Patients with Rheumatoid Arthritis. J Clin Immunol 2011; 31:596-605.

39. Herman S, Zurgil N, Machlav S, Shinberg A, Langevitz P, Ehrenfeld M et al. Distinct effects of anti-tumor necrosis factor combined therapy on TH1/TH2 balance in rheumatoid arthritis patients. Clin Vaccine Immunol 2011; 18(7):1077-1082: 
40. Chen DY, Chen YM, Chen HH, Hsieh CW, Lin CC, Lan JL. Increasing levels of circulating Th17 cells and interleukin-17 in rheumatoid arthritis patients with an inadequate response to anti-TNF-a therapy. Arthritis Res Ther 2011; 13:R126-135.

41. Blache C, Lequerré T, Roucheux A, Beutheu S, Dedreux I, Jacquot S et al. Number and phenotype of rheumatoid arthritis patients' CD4+CD25hi regulatory T cells are not affected by adalimumab or etanercept. Rheumatology (Oxford) 2011; 50(10):1814-1822

42. Bruns H, Meinken C, Schauenberg P, Härter G, Kern P, Modlin RL, et al. Anti-TNF immunotherapy reduces $\mathrm{CD} 8+\mathrm{T}$ cell-mediated antimicrobial activity against Mycobacterium tuberculosis in humans. J Clin Invest. 2009;119(5):1167-77.

43. Kikuchi J, Hashizume M, Kaneko Y, Yoshimoto K, Nishina N, Takeuchi T. Peripheral blood CD4+CD25+CD127low regulatory $\mathrm{T}$ cells are significantly increased by tocilizumab treatment in patients with rheumatoid arthritis: increase in regulatory $\mathrm{T}$ cells correlates with clinical response. Arthritis Res Ther 2015; 17:10-19.

44. Pesce B, Soto L, Sabugo F, Wurmann P, Cuchacovich M, López MN et al. Effect of interleukin- 6 receptor blockade on the balance between regulatory $\mathrm{T}$ cells and $\mathrm{T}$ helper type 17 cells in rheumatoid arthritis patients. Clin Exp Immunol 2013; 171(3):237-242.

45. Samson M, Audia S, Janikashvili N, Ciudad M, Trad M, Fraszczak J et al. Inhibition of interleukin-6 function corrects Th17/Treg cell imbalance in patients with rheumatoid arthritis. Arthritis Rheum 2012; 64(8):2499-2503.

46. Yang, PT, Kasai H, Zhao LJ, Xiao WG, Tanabe F, Ito M. Increased CCR4 expression on circulating CD4(+) $\mathrm{T}$ cells in ankylosing spondylitis, rheumatoid arthritis and systemic lupus erythematosus. Clin Exp Immunol 2004;138:342-7.

47. Jandus, CG, Bioley JP, Rivals JP, Dudler J, Speiser D, Romero P. Increased numbers of circulating polyfunctional Th17 memory cells in patients with seronegative spondylarthritides. Arthritis Rheum 2008;58:2307-17.

48. Limón-Camacho L, Vargas-Rojas MI, Vázquez-Mellado J, Casasola-Vargas J, Moctezuma JF, Burgos-Vargas R, et al.In vivo peripheral blood proinflammatory T cells in patients with ankylosing spondylitis .J Rheumatol. 2012;39(4):830-5.

49. Wang C, Liao Q, Hu Y, Zhong D. T lymphocyte subset imbalances in patients contribute to ankylosing spondylitis. Exp Ther Med 2015;9:250-256.

50. Wu Y, Ren M, Yang R et al. Reduced immunomodulation potential of bone marrowderived mesenchymal stem cells induced CCR4+CCR6+ Th/Treg cell subset imbalance in ankylosing spondylitis. Arthritis Res Ther 2011;13:R29. 
51. Venkatesha SH, Dudics S, Weingartner E, So EC, Pedra J, Moudgil KD. Altered Th17/Treg balance and dysregulated IL-1 $\beta$ response influence susceptibility/resistance to experimental autoimmune arthritis. Int J ImmunopatholPharmacol2015;28:318-28.

52. Xueyi L, Lina C, Zhenbiao W, Qing H, Qiang L, Zhu P. Levels of circulating Th17 cells and regulatory $\mathrm{T}$ cells in ankylosing spondylitis patients with an inadequate response to anti-TNF- $\alpha$ therapy. J Clin Immunol 2013;33:151-61.

53. Hull DN, Williams RO, Pathan E, Alzabin S, Abraham S, Taylor PC. Anti-tumour necrosis factor treatment increases circulating T helper type 17 cells similarly in different types of inflammatory arthritis. Clin Exp Immunol 2015;181:401-6.

54. Szalay B, Mészáros G, Cseh Á et al. Adaptive immunity in ankylosing spondylitis: phenotype and functional alterations of T-cells before and during infliximab therapy. Clin Dev Immunol 2012;2012:808724.

55. Liao HT, Lin YF, Tsai CY, Chou CT. Regulatory T cells in ankylosing spondylitis and the response after adalimumab treatment. Joint Bone Spine 2015;82:423-7.

56. Bautista-Caro MB, Arroyo-Villa I, Castillo-Gallego C et al. Decreased Th17 and Th1 cells in the peripheral blood of patients with early non-radiographic axial spondyloarthritis: a marker of disease activity in HLA-B27 ${ }^{+}$patients. Rheumatology (Oxford) 2013;52:35262.

57. Dulic S, Vásárhelyi Z, Sava F, Berta L, Szalay B, Toldi G, et al. T-cell subsets in rheumatoid arthritis patients on long-term anti- TNF or IL6-receptor-blocker therapy. Mediators Inflamm2017;2017:6894374

58. Fuss IJ, Neurath M, Boirivant M, Klein JS, de la Motte C, Strong SA, et al. Disparate CD4+ lamina propria (LP) lymphokine secretion profiles in inflammatory bowel disease. Crohn's disease LP cells manifest increased secretion of IFN-gamma, whereas ulcerative colitis LP cells manifest increased secretion of IL-5. J Immunol. 1996; 157(3):1261-70.

59. Globig AM, Hennecke N, Martin B, Seidl M, Ruf G, Hasselblatt P, et al. Comprehensive intestinal $\mathrm{T}$ helper cell profiling reveals specific accumulation of IFN- $\gamma+$ IL17+coproducing CD4+ T cells in active inflammatory bowel disease. Inflamm Bowel Dis. 2014;20(12):2321-9.

60. Ueno A, Jeffery L, Kobayashi T, Hibi T, Ghosh S, Jijon H. Th17 plasticity and its relevance to inflammatory bowel disease. J Autoimmun. 2018;87:38-49.

61. Fang D, Zhu J. Dynamic balance between master transcription factors determines the fates and functions of CD4 $\mathrm{T}$ cell and innate lymphoid cell subsets. J Exp Med. 2017;214(7):1861-1876. 
62. Li J, Ueno A, Iacucci M, Fort Gasia M, Jijon HB, Panaccione R, et al. Crossover Subsets of CD4+ T Lymphocytes in the Intestinal Lamina Propria of Patients with Crohn's Disease and Ulcerative Colitis. Dig Dis Sci. 2017;62(9):2357-2368.

63. Chamouard P, Monneaux F, Richert Z, Voegeli AC, Lavaux T, Gaub MP, et al. Diminution of Circulating CD4+CD25 high $\mathrm{T}$ cells in naïve Crohn's disease. Dig Dis Sci. 2009;54(10):2084-93.

64. Yokoyama Y, Fukunaga K, Ikeuchi H, Kamikozuru K, Hida N, Ohda Y, et al. The CD4+CD28null and the regulatory CD4+CD25High T-cell phenotypes in patients with ulcerative colitis during active and quiescent disease, and following colectomy. Cytokine. 2011;56(2):466-70.

65. Eastaff-Leung N, Mabarrack N, Barbour A, Cummins A, Barry S.Foxp3+ regulatory T cells, Th17 effector cells, and cytokine environment in inflammatory bowel disease. J Clin Immunol. 2010;30(1):80-9.

66. Mohammadnia-Afrouzi M, Zavaran Hosseini A, Khalili A, Abediankenari S, Hosseini V, Maleki I. Decrease of CD4(+) CD25(+) CD127(low) FoxP3(+) regulatory T cells with impaired suppressive function in untreated ulcerative colitis patients. Autoimmunity. 2015;48(8):556-61.

67. Takahashi M, Nakamura K, Honda K, Kitamura Y, Mizutani T, Araki Y, et al. An inverse correlation of human peripheral blood regulatory $\mathrm{T}$ cell frequency with the disease activity of ulcerative colitis. Dig Dis Sci. 2006;51(4):677-86.

68. Chao K, Zhang S, Yao J, He Y, Chen B, Zeng Z, et al. Imbalances of CD4(+) T-cell subgroups in Crohn's disease and their relationship with disease activity and prognosis. $\mathrm{J}$ Gastroenterol Hepatol. 2014;29(10):1808-14.

69. Dong Z, Du L, Xu X, Yang Y, Wang H, Qu A et al. Aberrant expression of circulating Th17, Th1 and Tc1 cells in patients with active and inactive ulcerative colitis. Int J Mol Med. 2013;31(4):989-97.

70. Funderburg NT, Stubblefield Park SR, Sung HC, Hardy G, Clagett B, Ignatz-Hoover J, et al. Circulating CD4+ and CD8+ T cells are activated in inflammatory bowel disease and are associated with plasma markers of inflammation. Immunology. 2013; 140(1): 87-97

71. Ueno A, Jijon H, Chan R, Ford K, Hirota C, Kaplan GG, et al. Increased prevalence of circulating novel IL-17 secreting Foxp3 expressing CD4+ $\mathrm{T}$ cells and defective suppressive function of circulating Foxp3+ regulatory cells support plasticity between Th17 and regulatory T cells in inflammatory bowel disease patients. Inflamm Bowel Dis. 2013;19(12):2522-34. 
72. Dai S, Gu H, Lin Q, Wu Y, Wang X, Huang S, et al. Decreased CD8+CD28+/CD8+CD28$\mathrm{T}$ cell ratio can sensitively predict poor outcome for patients with complicated Crohn disease. Medicine (Baltimore) 2017; 96(26):

73. Hvas CL, Kelsen J, Agnholt J, Dige A, Christensen LA, Dahlerup JF. Discrete changes in circulating regulatory $\mathrm{T}$ cells during infliximab treatment of Crohn's disease. Autoimmunity. 2010;43(4):325-33.

74. Dige A, Hvas CL, Deleuran B, Kelsen J, Bendix-Struve M, Dahlerup JF, Agnholt J. Adalimumab treatment in Crohn's disease does not induce early changes in regulatory $\mathrm{T}$ cells. Scand J Gastroenterol. 2011;46(10):1206-14.

75. Di Sabatino A, Biancheri P, Piconese S, Rosado MM, Ardizzone S, Rovedatti L, et al. Peripheral regulatory $\mathrm{T}$ cells and serum transforming growth factor- $\beta$ : relationship with clinical response to infliximab in Crohn's disease .Inflamm Bowel Dis. 2010;16(11):18917.

76. Wang Y, Liu XP, Zhao ZB, Chen JH, Yu CG. Expression of CD4+ forkhead box P3 (FOXP3)+ regulatory T cells in inflammatory bowel disease. J Dig Dis. 2011;12(4):28694.

77. Li Z, Arijs I, De Hertogh G, Vermeire S, Noman M, Bullens D, Coorevits L, et al. Reciprocal changes of Foxp3 expression in blood and intestinal mucosa in IBD patients responding to infliximab. Inflamm Bowel Dis. 2010;16(8):1299-310.

78. Li Z, Vermeire S, Bullens D, Ferrante M, Van Steen K, Noman M, et al. Restoration of Foxp3+ Regulatory T-cell Subsets and Foxp3- Type 1 Regulatory-like T Cells in Inflammatory Bowel Diseases During Anti-tumor Necrosis Factor Therapy. Inflamm Bowel Dis. 2015;21(10):2418-28.

79. Guidi L, Felice C, Procoli A, Bonanno G, Martinelli E, Marzo M, et al. FOXP3 ${ }^{+}$T regulatory cell modifications in inflammatory bowel disease patients treated with antiTNF $\alpha$ agents. Biomed Res Int. 2013;2013:286368.

80. Boschetti G, Nancey S, Sardi F, Roblin X, Flourié B, Kaiserlian D. Therapy with anti$\mathrm{TNF} \alpha$ antibody enhances number and function of Foxp3(+) regulatory $\mathrm{T}$ cells in inflammatory bowel diseases. Inflamm Bowel Dis. 2011;17(1):160-70.

81. Grundström J, Linton L, Thunberg S, Forsslund H, Janczewska I, Befrits R, et al. Altered immunoregulatory profile during anti-tumour necrosis factor treatment of patients with inflammatory bowel disease. Clin Exp Immunol. 2012;169(2):137-47.

82. Aletaha D, Neogi T, Silman AJ, Funovits J, Felson DT, Bingham CO et al. 2010 Rheumatoid Arthritis Classification Criteria. An American College of 
Rheumatology/European League Against Rheumatism Collaborative Initiative. Arthritis Rheum 2010; 62 (9): 2569-2581.

83. van Gestel AM, Haagsma CJ, van Riel PL. Validation of rheumatoid arthritis improvement criteria that include simplified joint counts. Arthritis Rheum 1998; 41(10):1845-1850.

84. van der Linden, S., Valkenburg HA, Cats A. Evaluation of diagnostic criteria for ankylosing spondylitis. A proposal for modification of the New York criteria. Arthritis Rheum 1984;27:361-8.

85. Brandt J, Listing J,Sieper J, Rudwaleit M, van der Heijde D, Braun J. Development and preselection of criteria for short term improvement after anti-TNF alpha treatment in ankylosing spondylitis. Ann Rheum Dis 2004;63:1438-44.

86. Anderson JJ, Baron G, van der Heijde D, Felson DT, Dougados M. Ankylosing spondylitis assessment group preliminary definition of short-term improvement in ankylosing spondylitis. Arthritis Rheum 2001;44:1876-86.

87. Best WR, Becktel JM, Singleton JW, Kern F Jr. Development of a Crohn's disease activity index. National Cooperative Crohn's Disease Study. Gastroenterology.1976; 70 (3): 439444.

88. Colombel JF, Schwartz DA, Sandborn WJ, Kamm MA, D'Haens G, Rutgeerts P, et al. Adalimumab for the treatment of fistulas in patients with Crohn's disease. Gut 2009; 58(7):940-8;

89. Schroeder KW, Tremaini WJ, Ilstrup DM. Coated oral 5-aminosalicylic acid for treatment of mildly to moderately active ulcerative colitis. A randomized study. N Engl J Med 1978; 317:1625-1629.

90. Satsangi J, Silverberg MS, Vermeire S, Colombel JF. The Montreal classification of inflammatory bowel disease: controversies, consensus, and implications. Gut 2006; 55(6): $749-753$.

91. Lewis JD, Chuai S, Nessel L, Lichtenstein GR, Aberra FN, Ellenberg JH. Use of the Noninvasive Components of the Mayo Score to Assess Clinical Response in Ulcerative Colitis. Inflamm Bowel Dis. 2008; 14(12): 1660-1666;

92. Sands B, Anderson F, Bernstein C, Chey W, Feagan B, Fedorak R, et al. Infliximab maintenance therapy for fistulizing Crohn's disease. N Engl J Med. 2004; 350 (9): 876-85.

93. Cope AP, Londei M, Chu NR, Cohen SB, Elliott MJ, Brennan FM, et al. Chronic exposure to tumor necrosis factor (TNF) in vitro impairs the activation of T cells through the $\mathrm{T}$ cell receptor/CD3 complex; reversal in vivo by anti-TNF antibodies in patients with rheumatoid arthritis. J Clin Invest 1994;94:749-760 
94. Speiser DE, Sebzda E, Ohteki T, Bachmann MF, Pfeffer K, Mak TW, et al. Tumor necrosis factor receptor p55 mediates deletion of peripheral cytotoxic T lymphocytes in vivo. Eur $\mathrm{J}$ Immunol 1996; 26:3055-3060

95. Ueda N, Tsukamoto H, Mitoma H, Ayano M, Tanaka A, Ohta S, et al The cytotoxic effects of certolizumab pegol and golimumab mediated by transmembrane tumor necrosis factor a. Inflamm Bowel Dis 2013;19:1224-1231

96. Teniente-Serra A, Grau-López L, Mansilla MJ, Fernández-Sanmartín M, Ester Condins A, Ramo-Tello C et al. Multiparametric flow cytometric analysis of whole blood reveals changes in minor lymphocyte subpopulations of multiple sclerosis patients. Autoimmunity 2016; 49(4):219-228.

97. Aerts NE, De Knop KJ, Leysen J et al. Increased IL-17 production by peripheral T helper cells after tumour necrosis factor blockade in rheumatoid arthritis is accompanied by inhibition of migration-associated chemokine receptor expression. Rheumatology 2010; 49:2264-72.

98. Talotta R, Berzi A, Atzeni F, Batticciotto A, Clerici M, Sarzi-Puttini P, Trabattoni D. Paradoxical Expansion of Th1 and Th17 Lymphocytes in Rheumatoid Arthritis Following Infliximab Treatment: a Possible Explanation for a Lack of Clinical Response. J Clin Immunol. 2015;35:550-7

99. Notley CA, Inglis JJ, Alzabin S, McCann FE, McNamee KE, Williams RO. Blockade of tumor necrosis factor in collagen induced arthritis reveals a novel immunoregulatory pathway for Th1 and Th17 cells. J Exp Med 2008; 205:2491-7.

100. Suresh M, Singh A, Fischer C. Role of tumor necrosis factor receptors in regulating CD8 T-cell responses during acute lymphocytic choriomeningitis virus infection. J Virol 2005;79:202-213 